\title{
ON THE DERIVATIVE-FREE QUASI-NEWTON-TYPE ALGORITHM FOR SEPARABLE SYSTEMS OF NONLINEAR EQUATIONS
}

\author{
Hassan Mohammad ${ }^{1,2, *} \odot$, Aliyu Muhammed Awwal ${ }^{2,3,4} \odot$, \\ Auwal Bala Abubakar ${ }^{1,2,5}$ e and Ahmad Salihu Ben Musa ${ }^{6} \odot$
}

\begin{abstract}
A derivative-free quasi-Newton-type algorithm in which its search direction is a product of a positive definite diagonal matrix and a residual vector is presented. The algorithm is simple to implement and has the ability to solve large-scale nonlinear systems of equations with separable functions. The diagonal matrix is simply obtained in a quasi-Newton manner at each iteration. Under some suitable conditions, the global and R-linear convergence result of the algorithm are presented. Numerical test on some benchmark separable nonlinear equations problems reveal the robustness and efficiency of the algorithm.
\end{abstract}

Mathematics Subject Classification. 65K05, 65H10, 90C30, 90C53.

Received December 27, 2020. Accepted October 9, 2021.

\section{INTRODUCTION}

Consider the problem of finding a solution of nonlinear system of equations

$$
g(x)=0
$$

where $g=\left(g_{1}, g_{2}, \ldots g_{n}\right): \mathbb{R}^{n} \rightarrow \mathbb{R}^{n}$ is a separable function. The separability here means each of the component $g_{i}$ depends on only one or a few components of the vector $x$. This structure has been studied and regarded as partial separability by Griewank and Toint in [6-8].

\footnotetext{
Keywords. Separable nonlinear equations, derivative-free methods, quasi-Newton-type methods, convergence, numerical experiments.

1 Department of Mathematical Sciences, Faculty of Physical Sciences, Bayero University, Kano, Nigeria.

2 Numerical Optimization Research Group, Bayero University, Kano, Nigeria.

3 Department of Mathematics, Faculty of Science, Gombe State University, Gombe, Nigeria.

4 KMUTT Fixed Point Research Laboratory, Room SCL 802 Fixed Point Laboratory, Science Laboratory Building, Department of Mathematics, Faculty of Science, King Mongkut's University of Technology Thonburi (KMUTT), 126 Pracha-Uthit Road, Bang Mod, Thrung Khru, Bangkok 10140, Thailand.

5 Department of Mathematics and Applied Mathematics, Sefako Makgatho Health Sciences University, Ga-Rankuwa, Pretoria, Medunsa 0204, South Africa.

6 Department of Computer Science, Federal College of Agricultural Produce Technology, Kano, Nigeria.

* Corresponding author: hmuhd.mth@buk.edu.ng
} 
Problem (1.1) may arise from an unconstrained optimization problem, for example, let $f(x)=\sum_{i=1}^{n} g_{i}(x)$. Then the nonlinear system of equations problem (1.1) is equivalent to the unconstrained optimization problem

$$
\min f(x), \quad x \in \mathbb{R}^{n} .
$$

For finding the solution of general nonlinear equations, quasi-Newton methods are famous and commonly used algorithms because of their derivative-free nature [17,21]. However, among these methods, some are not suitable for large-scale problems due to matrix storage requirements. As such, methods that considered nonlinear equations with structured functions are given much attention. Nevertheless, several quasi-Newton-type alternatives are given over the last decade (see for example $[14,18,19,23,25,27]$ ). The spectral gradient method initially introduced by Barzilai and Borwein has been successfully used as a derivative-free approach for solving large-scale nonlinear equations by La Cruz-Martínez-Raydan in [11,13]. Specifically, La Cruz et al. [13] presented a derivative-free spectral residual method (dfsane) for solving large-scale nonlinear equations. The algorithm uses a scalar multiple of identity for estimating the Jacobian of the function $g$. Moreover, some algorithms that uses a diagonal matrix to approximate the Jacobian of the residual function $g$ have been studied in the literature. For details, interested reader may refer to the following references $[5,10,24,26]$.

In this paper, we incorporate the diagonal Hessian approximation approach studied by Deng and Wan [2] and the spectral residual approach presented in [13] to propose, analyze and implement a derivative-free algorithm for separable problems, which can be seen as an improved version of the dfsane algorithm that used a positive definite diagonal matrix as the approximation of the Jacobian of the function $g$. A derivative-free line search is employed to analyze the convergence of the proposed algorithm.

The paper is organized as follows. Section 2 describes some preliminaries and the algorithm. Section 3 addresses the global convergence and rate of convergence results of the algorithm. Section 4 presents the numerical experiments, and conclusions are given in Section 5. Unless otherwise stated, throughout this paper we denote $u_{k}^{i}$ to refer to the $i$ th component of a vector $u_{k}$. Also, $\|\cdot\|$ stands for the Euclidean norm of vectors and the induced 2-norm of matrices.

\section{Preliminaries AND ALGORIthm}

In this section, we present the derivative-free quasi-Newton-type algorithm. We begin by briefly reviewing the conference paper by Deng and Wan [2].

Based on the idea of Shi and Sun in [22], Deng and Wan presented a spectral conjugate gradient method for solving unconstrained optimization problem (1.2), in which the spectral parameter is a specific diagonal matrix chosen such that it owns some quasi-Newton property. They considered a diagonal matrix $Q_{k}=\operatorname{diag}\left(q_{k}^{1}, q_{k}^{2}, \ldots, q_{k}^{n}\right)$, and solved the following constrained optimization problem

$$
\min _{L_{k} \leq q_{k}^{i} \leq U_{k}} \frac{1}{2} \sum_{i=1}^{n}\left(q_{k}^{i} y_{k-1}^{i}-s_{k-1}^{i}\right)^{2},
$$

where $L_{k}$ and $U_{k}$ are given lower and upper bounds for $q_{k}^{i}$ such that $0<L_{k} \leq q_{k}^{i} \leq U_{k}$, and so $Q_{k}$ is a safely positive definite matrix. The solution of the problem (2.1) is given by

$$
q_{k}^{i}= \begin{cases}\frac{s_{k-1}^{i}}{y_{k-1}^{i}}, & \text { if } L_{k} \leq \frac{s_{k-1}^{i}}{y_{k-1}^{i}} \leq U_{k} \\ L_{k}, & \text { if } \frac{s_{k-1}^{i}}{y_{k-1}^{i}}<L_{k} \\ U_{k}, & \text { if } \frac{s_{k-1}^{i}}{y_{k-1}^{i}}>U_{k} \\ \frac{L_{k}+U_{k}}{2}, & \text { if } y_{k-1}^{i}=0,\end{cases}
$$


where $L_{k}=c_{1}\left\|g_{k}\right\|, U_{k}=c_{1}\left\|g_{k}\right\|+c_{2}$ and $c_{1}, c_{2}>0$. Unfortunately, the authors in [2] do not present numerical implementation of the method.

Next, to build our propose algorithm, we begin by assembling the diagonal matrix similar to the one proposed by Deng and Wan. The difference between the former and later is on the safeguard that ensure positive definiteness of the diagonal matrix. To construct the diagonal matrix of the proposed algorithm, we make use of the following Lemma (Lemma 1 in [20]).

Lemma 2.1. Let $D=\operatorname{diag}(d)$ be a diagonal matrix in $\mathbb{R}^{n \times n}$, and let $u$ and $v$ be vectors in $\mathbb{R}^{n}$. Then, the solution of the constrained linear least-squares problem with simple bounds

$$
\begin{aligned}
& \min _{d \in \mathbb{R}^{n}} \frac{1}{2}\|\operatorname{diag}(d) v-u\|^{2}, \\
& \text { subject to }-d \leq 0,
\end{aligned}
$$

is given by

$$
d^{i}=\left\{\begin{array}{ll}
\frac{u^{i}}{v^{i}}, & \text { if } \frac{u^{i}}{v^{i}}>0, \\
0, & \text { if } \frac{u^{i}}{v^{i}} \leq 0 \text { or } v^{i}=0 .
\end{array} \quad i=1,2, \ldots, n .\right.
$$

Based on the results of Lemma 2.1, the resulting diagonal matrix is positive semi-definite. However, to obtain a descent direction that will be used with a suitable line search technique, we define a positive definite diagonal matrix $D_{k}(k \geq 1)$ with entries

$$
d_{k}^{i}=\left\{\begin{array}{ll}
\frac{y_{k-1}^{i}}{s_{k-1}^{i}}, & \text { if } \frac{y_{k-1}^{i}}{s_{k-1}^{i}}>0, \\
1, & \text { if } \frac{y_{k-1}^{i}}{s_{k-1}^{i}} \leq 0 \text { or } s_{k-1}^{i}=0
\end{array} i=1,2, \ldots, n\right.
$$

where $s_{k-1}=x_{k}-x_{k-1}$ and $y_{k-1}=g\left(x_{k}\right)-g\left(x_{k-1}\right)$. The search direction of the diagonal derivative-free method is obtained as a solution of the linear system:

$$
D_{k} p_{k}+g\left(x_{k}\right)=0
$$

where

$$
D_{k}= \begin{cases}\operatorname{diag}\left(d_{k}^{1}, d_{k}^{2}, \ldots, d_{k}^{n}\right), & \text { if } k \geq 1 \\ I, & \text { if } k=0\end{cases}
$$

is a diagonal matrix, whose entries are computed using equation (2.3).

Furthermore, we safeguard $D_{k}$ for very small and very large values by means of a projection of its entries into a given scalar interval $[\underline{d}, \bar{d}]$ such that $0<\underline{d}<1$ and $\bar{d} \geq 1$. Hence, the $i$-th entry of the matrix $D_{k}$ is

$$
d_{k}^{i}=\left\{\begin{array}{ll}
\max \left\{\min \left\{\frac{y_{k-1}^{i}}{s_{k-1}^{i}}, \bar{d}\right\}, \underline{d}\right\}, & \text { if } s_{k-1}^{i} \neq 0 \\
1, & \text { if } s_{k-1}^{i}=0 .
\end{array} i=1,2, \ldots, n .\right.
$$

It can be seen from equation (2.6), the sequence $\left\{d_{k}^{i}\right\}$ is uniformly bounded for each $i$ and $k$. In fact, $0<\underline{d} \leq$ $d_{k}^{i} \leq \bar{d} \forall i, \forall k$. Consequently, $D_{k}$ is invertible for each $k \geq 0$.

In contrast to the diagonal matrix proposed by Deng and Wan [2], the safeguard procedure here is simple, as it set the nonpositive entries of the generated diagonal matrix to a nonnegative parameter $\underline{d}$, and the undefined entries to 1. Thus, at a certain iterate where some of the entries of the diagonal matrix becomes undefined, the entries are set to 1 . Unlike Deng and Wan proposed diagonal matrix, where the undefined entries are set to the average of the lower and upper bounds $L_{k}$ and $U_{k}$. The detail steps of the derivative-free quasi-Newton-type approach is given below. 


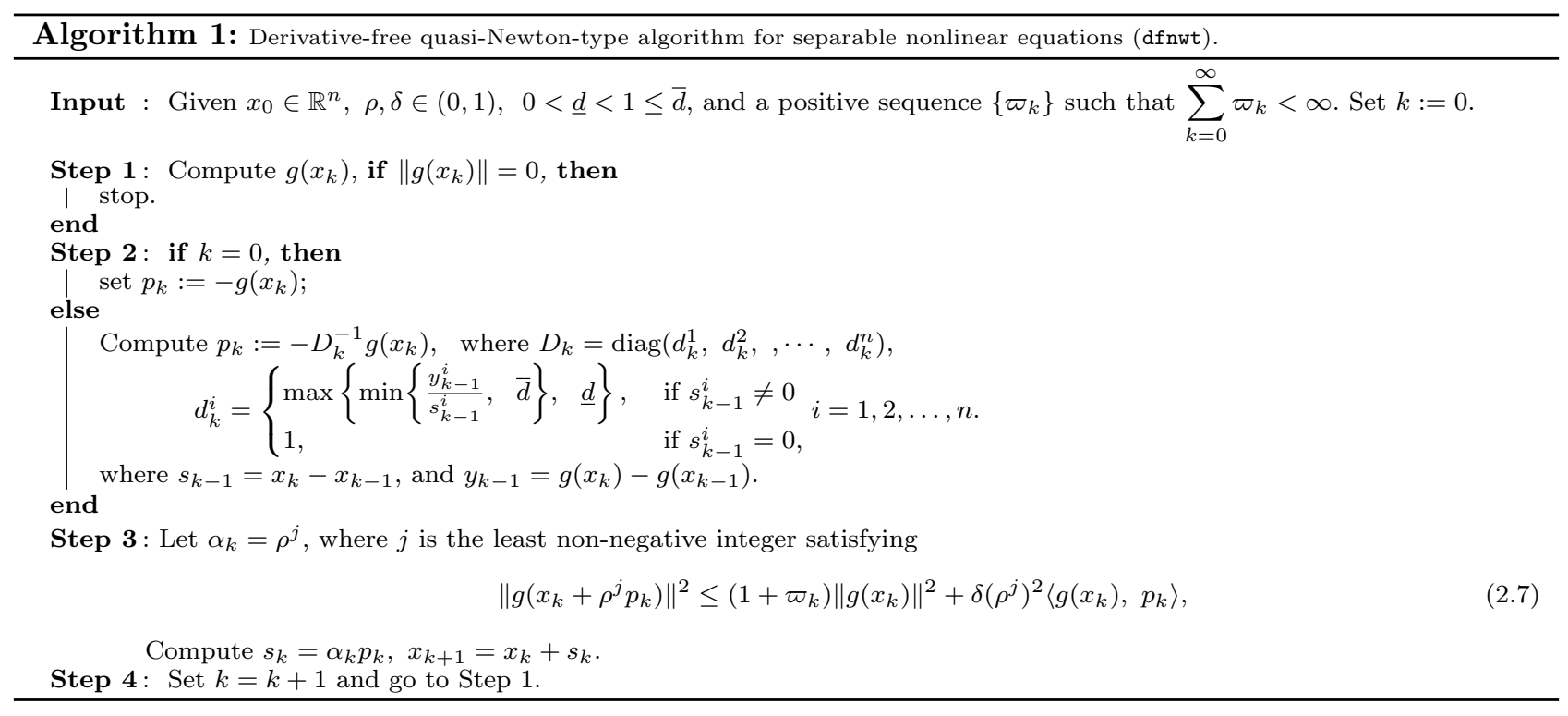

Remark 2.2. Since the matrix $D_{k}$ is diagonal, the product at Step 2 of Algorithm 1 when $k \neq 0$ is simply the product between the diagonal elements of $D_{k}^{-1}$ and the corresponding components of $g\left(x_{k}\right)$, computed in $O(n)$ operations.

Remark 2.3. By the definition of the search direction in Step 2, it can be deduce easily that,

$$
\frac{1}{\bar{d}}\left\|g\left(x_{k}\right)\right\| \leq\left\|p_{k}\right\| \leq \frac{1}{\underline{d}}\left\|g\left(x_{k}\right)\right\| .
$$

Remark 2.4. The line search condition (2.7) has some similarity to the one used in [29]. The right hand side of the current line search in (2.7) has an additional term, a positive sequence that guaranty the well-definedness of the inequality. In fact, for sufficiently large $k$, the inequality (2.7) holds as the stepsize $\alpha_{k} \rightarrow 0^{+}$. Thus, $\alpha_{k}$ can be obtained by some backtracking approach such as Step 3 of Algorithm 1.

\section{Convergence Results}

In this section, we prove the global and R-linear convergence of Algorithm 1. First we assume that $g\left(x_{k}\right) \neq 0$ for any $k \geq 0$ except at the solution.

Furthermore, we assume the following:

Assumption 3.1. (i.) The function $g: \Theta \subseteq \mathbb{R}^{n} \rightarrow \mathbb{R}^{n}$ is continuously differentiable on $\Theta$.

(ii.) The Jacobian $J$ of $g$ at $x$, denoted by $J(x)$, is bounded and uniformly nonsingular on $\Theta$, i.e., there exist nonnegative scalars $\varepsilon_{1}, \varepsilon_{2}$ such that

$$
\begin{gathered}
\varepsilon_{1} \leq\|J(x)\| \leq \varepsilon_{2}, \quad \text { for all } \quad x \in \Theta, \\
\frac{1}{\varepsilon_{2}} \leq\left\|J(x)^{-1}\right\| \leq \frac{1}{\varepsilon_{1}} \quad \text { for all } \quad x \in \Theta .
\end{gathered}
$$

(iii.) The Jacobian $J$ is Lipschitz continuous with Lipschitz constant $\gamma$ on $\Theta$. That is,

$$
\|J(x)-J(y)\| \leq \gamma\|x-y\|, \quad \text { for all } x, y \in \Theta .
$$


Assumption 3.1 implies that there is constants $M \geq m>0$ such that

$$
m\|x-y\| \leq\|g(x)-g(y)\| \leq M\|x-y\|, \quad \forall x, y \in \mathbb{R}^{n} .
$$

Assumption 3.2. The diagonal matrix $D_{k}$ approximate the Jacobian matrix $J$ of the function $g$ at $x_{k}$ along the direction $p_{k}$, therefore, $D_{k}$ can be regarded as a good approximation of $J\left(x_{k}\right)$. That is,

$$
\left\|\left(D_{k}-J\left(x_{k}\right)\right) p_{k}\right\| \leq r\left\|g\left(x_{k}\right)\right\|, \text { for all } k \geq 0,
$$

where $r \in(0,1)$ is a very small constant.

Lemma 3.3. Let the sequence $\left\{x_{k}\right\}$ be generated by Algorithm 1, then for all $k \geq 0$

(a)

$$
\frac{1}{\bar{d}}\left\|g\left(x_{k}\right)\right\|^{2} \leq-\left\langle g\left(x_{k}\right), p_{k}\right\rangle \leq \frac{1}{\underline{d}}\left\|g\left(x_{k}\right)\right\|^{2},
$$

(b)

$$
\left\langle g\left(x_{k}\right), J\left(x_{k}\right) p_{k}\right\rangle \leq-(1-r)\left\|g\left(x_{k}\right)\right\|^{2},
$$

(c)

$$
-\bar{d}\left\|p_{k}\right\|^{2} \leq\left\langle g\left(x_{k}\right), p_{k}\right\rangle \leq-\underline{d}\left\|p_{k}\right\|^{2} .
$$

Proof. (a) For $k=0$,

$$
\begin{aligned}
-\left\langle g\left(x_{0}\right), p_{0}\right\rangle & =-\left\langle g\left(x_{0}\right),-D_{0}^{-1} g\left(x_{0}\right)\right\rangle \\
& =\left\|g\left(x_{0}\right)\right\|^{2}, \text { since } D_{0}=I .
\end{aligned}
$$

For $k \geq 1$,

$$
\begin{aligned}
-\left\langle g\left(x_{k}\right), p_{k}\right\rangle & =-\left\langle g\left(x_{k}\right),-D_{k}^{-1} g\left(x_{k}\right)\right\rangle \\
& =\left\langle g\left(x_{k}\right), \operatorname{diag}\left(\frac{1}{d_{k}^{1}}, \frac{1}{d_{k}^{2}}, \cdots, \frac{1}{d_{k}^{n}}\right) g\left(x_{k}\right)\right\rangle \\
& \leq\left\langle g\left(x_{k}\right), \operatorname{diag}\left(\frac{1}{d}, \frac{1}{\underline{d}}, \cdots, \frac{1}{\underline{d}}\right) g\left(x_{k}\right)\right\rangle \\
& =\frac{1}{\underline{d}}\left\|g\left(x_{k}\right)\right\|^{2} .
\end{aligned}
$$

On the other hand,

$$
\begin{aligned}
-\left\langle g\left(x_{k}\right), p_{k}\right\rangle & =-\left\langle g\left(x_{k}\right),-D_{k}^{-1} g\left(x_{k}\right)\right\rangle \\
& =\left\langle g\left(x_{k}\right), \operatorname{diag}\left(\frac{1}{d_{k}^{1}}, \frac{1}{d_{k}^{2}}, \cdots, \frac{1}{d_{k}^{n}}\right) g\left(x_{k}\right)\right\rangle \\
& \geq\left\langle g\left(x_{k}\right), \operatorname{diag}\left(\frac{1}{\bar{d}}, \frac{1}{\bar{d}}, \cdots, \frac{1}{\bar{d}}\right) g\left(x_{k}\right)\right\rangle \\
& =\frac{1}{\bar{d}}\left\|g\left(x_{k}\right)\right\|^{2} .
\end{aligned}
$$

Combining (3.6) and (3.7), we obtain (3.3). 
(b) For $k \geq 0$, equality (2.4) together with inequality (3.2) gives

$$
\begin{aligned}
\left\langle g\left(x_{k}\right), J\left(x_{k}\right) p_{k}\right\rangle & =\left\langle g\left(x_{k}\right), J\left(x_{k}\right) p_{k}-\left(D_{k} p_{k}+g\left(x_{k}\right)\right)\right\rangle \\
& =\left\langle g\left(x_{k}\right),\left(J\left(x_{k}\right)-D_{k}\right) p_{k}\right\rangle-\left\|g\left(x_{k}\right)\right\|^{2} \\
& \leq\left\|g\left(x_{k}\right)\right\|\left\|\left(J\left(x_{k}\right)-D_{k}\right) p_{k}\right\|-\left\|g\left(x_{k}\right)\right\|^{2} \\
& \leq r\left\|g\left(x_{k}\right)\right\|^{2}-\left\|g\left(x_{k}\right)\right\|^{2} \\
& =-(1-r)\left\|g\left(x_{k}\right)\right\|^{2} .
\end{aligned}
$$

The proof of (c) follows directly from equation (2.4) and the definition of $D_{k}$ in (2.5)-(2.6).

The following Lemma is from [3].

Lemma 3.4. Let $\left\{a_{k}\right\}$ and $\left\{e_{k}\right\}$ be nonnegative sequences such that

$$
a_{k+1} \leq\left(1+e_{k}\right) a_{k} \text { and } \sum_{k=0}^{\infty} e_{k}<\infty
$$

then the sequence $\left\{a_{k}\right\}$ has a limit in $\mathbb{R}$.

Lemma 3.5. Let $\left\{x_{k}\right\}$ be the sequence generated by Algorithm 1, then we have

(a) $\left\{\left\|g\left(x_{k}\right)\right\|\right\}$ is convergent.

(b) $\lim _{k \rightarrow \infty}-\alpha_{k}^{2}\left\langle g\left(x_{k}\right), p_{k}\right\rangle=0$.

Proof. (a) Setting $a_{k}=\left\|g\left(x_{k}\right)\right\|^{2}$ and $e_{k}=\varpi_{k}$ in Lemma 3.4, we have

$$
\left\|g\left(x_{k+1}\right)\right\|^{2} \leq\left(1+\varpi_{k}\right)\left\|g\left(x_{k}\right)\right\|^{2} .
$$

Since $\left\|g\left(x_{k}\right)\right\|^{2} \geq 0$ and $\sum_{k=0}^{\infty} \varpi_{k}<\infty$, it holds $\left\{\left\|g\left(x_{k}\right)\right\|\right\}$ is convergent.

(b) Using (2.7), we can get for any $k$

$$
-\delta \alpha_{k}^{2}\left\langle g\left(x_{k}\right), p_{k}\right\rangle \leq\left\|g\left(x_{k}\right)\right\|^{2}-\left\|g\left(x_{k+1}\right)\right\|^{2}+\varpi_{k}\left\|g\left(x_{k}\right)\right\|^{2} .
$$

Summing both sides of (3.8) yields

$$
\delta \sum_{k=0}^{\infty}-\alpha_{k}^{2}\left\langle g\left(x_{k}\right), p_{k}\right\rangle \leq\left\|g\left(x_{0}\right)\right\|+\sum_{k=0}^{\infty} \varpi_{k}\left\|g\left(x_{k}\right)\right\|^{2} .
$$

Since $\left\{\left\|g\left(x_{k}\right)\right\|\right\}$ converges for all $k, \sum_{k=0}^{\infty} \varpi_{k}$ is convergent and $\delta$ is a positive constant, it follows that

$$
\sum_{k=0}^{\infty}-\alpha_{k}^{2}\left\langle g\left(x_{k}\right), p_{k}\right\rangle<\infty
$$

Hence,

$$
\lim _{k \rightarrow \infty}-\alpha_{k}^{2}\left\langle g\left(x_{k}\right), p_{k}\right\rangle=0
$$


Lemma 3.6. Suppose Assumptions 3.1 and 3.2 hold. Let $\left\{x_{k}\right\}$ be a sequence of iterates generated by Algorithm 1. Then

$$
\alpha_{k} \geq \min \left\{1, \frac{2 \rho \underline{d}^{2}(1-r)}{\delta \bar{d}}\right\}
$$

for all sufficiently large $k$.

Proof. By the line search condition (2.7) if $\alpha_{k} \neq 1$, then $\frac{\alpha_{k}}{\rho}$ does not satisfy (2.7), that is

$$
\left\|g\left(x_{k}+\frac{\alpha_{k}}{\rho} p_{k}\right)\right\|^{2}>\left(1+\varpi_{k}\right)\left\|g\left(x_{k}\right)\right\|^{2}+\delta \frac{\alpha_{k}^{2}}{\rho^{2}}\left\langle g\left(x_{k}\right), p_{k}\right\rangle .
$$

This gives

$$
-\delta \frac{\alpha_{k}^{2}}{\rho^{2}}\left\langle g\left(x_{k}\right), p_{k}\right\rangle>\left\|g\left(x_{k}\right)\right\|^{2}-\left\|g\left(x_{k}+\frac{\alpha_{k}}{\rho} p_{k}\right)\right\|^{2} .
$$

Using the right hand side of (3.11), inequalities (2.8), (3.4) and (3.5), we have

$$
\begin{aligned}
\left\|g\left(x_{k}\right)\right\|^{2}-\left\|g\left(x_{k}+\frac{\alpha_{k}}{\rho} p_{k}\right)\right\|^{2} & =-2 \frac{\alpha_{k}}{\rho}\left\langle g\left(x_{k}\right), J\left(x_{k}\right) p_{k}\right\rangle+o\left(\frac{\alpha_{k}}{\rho}\left\|p_{k}\right\|\right) \\
& \geq 2 \frac{\alpha_{k}}{\rho}(1-r)\left\|g\left(x_{k}\right)\right\|^{2}+o\left(\frac{\alpha_{k}}{\rho}\left\|p_{k}\right\|\right) \\
& \geq 2 \underline{d}^{2} \frac{\alpha_{k}}{\rho}(1-r)\left\|p_{k}\right\|^{2}+o\left(\frac{\alpha_{k}}{\rho}\left\|p_{k}\right\|\right) \\
& \geq-2 \underline{d}^{2} \frac{\alpha_{k}}{\rho \bar{d}}(1-r)\left\langle g\left(x_{k}\right), p_{k}\right\rangle,
\end{aligned}
$$

where $o: \mathbb{R}_{+} \rightarrow \mathbb{R}$ is such that $\lim _{\xi \rightarrow 0} \frac{o(\xi)}{\xi}=0$.

Combining (3.11) and (3.12), we have

$$
\alpha_{k}>\frac{2 \rho \underline{d}^{2}(1-r)}{\delta \bar{d}}
$$

which means that (3.10) holds.

Theorem 3.7. Suppose Assumptions 3.1 and 3.2 hold. If the sequence $\left\{x_{k}\right\}$ is generated by Algorithm 1, then

$$
\lim _{k \rightarrow \infty}\left\|g\left(x_{k}\right)\right\|=0 .
$$

Proof. By Lemma 3.6, there exists a nonnegative scalar say

$$
\bar{\alpha}:=\min \left\{1, \frac{2 \underline{d}^{2}(1-r)}{\delta \bar{d}}\right\} \leq \alpha_{k}
$$

It follows from (3.3) and (3.14) that

$$
-\alpha_{k}^{2}\left\langle g\left(x_{k}\right), p_{k}\right\rangle \geq \frac{\alpha_{k}^{2}}{\bar{d}}\left\|g\left(x_{k}\right)\right\|^{2} \geq \frac{\bar{\alpha}^{2}}{\bar{d}}\left\|g\left(x_{k}\right)\right\|^{2} \geq 0 .
$$

Therefore, using (3.9), we have

$$
0=\lim _{k \rightarrow \infty}-\alpha_{k}^{2}\left\langle g\left(x_{k}\right), p_{k}\right\rangle \geq \frac{\bar{\alpha}^{2}}{\bar{d}} \lim _{k \rightarrow \infty}\left\|g\left(x_{k}\right)\right\|^{2} \geq 0 .
$$

This gives (3.13). 
We now present the R-liner convergence of Algorithm 1.

Theorem 3.8. Suppose Assumption 3.1 holds. If the sequence $\left\{x_{k}\right\}$ generated by Algorithm 1 converges to $x^{*}$, then for sufficiently large $k$, there exist constants $C>0$ and $\mu \in(0,1)$ such that

$$
\left\|x_{k}-x^{*}\right\| \leq C \mu^{k}
$$

Proof. From the line search condition (2.7), it follows that

$$
\begin{aligned}
\left\|g\left(x_{k+1}\right)\right\|^{2} & \leq\left(1+\varpi_{k}\right)\left\|g\left(x_{k}\right)\right\|^{2}+\delta \alpha_{k}^{2}\left\langle g\left(x_{k}\right), p_{k}\right\rangle \\
& \leq\left(1+\varpi_{k}\right)\left\|g\left(x_{k}\right)\right\|^{2}-\delta \alpha_{k}^{2} \frac{1}{\bar{d}}\left\|g\left(x_{k}\right)\right\|^{2} \\
& \leq\left(1+\varpi_{k}\right)\left\|g\left(x_{k}\right)\right\|^{2}-\delta \bar{\alpha}^{2} \frac{1}{\bar{d}}\left\|g\left(x_{k}\right)\right\|^{2} \\
& =\left(1-\delta \bar{\alpha}^{2} \frac{1}{\bar{d}}+\varpi_{k}\right)\left\|g\left(x_{k}\right)\right\|^{2},
\end{aligned}
$$

where the second and third inequalities follow from (3.3) and (3.14) respectively. Since $\varpi_{k} \rightarrow 0$, without loss of generality, we assume that $\varpi_{k} \leq \delta \bar{\alpha}^{2} \frac{1}{2 \bar{d}}$ for all $k$ so that

$$
\left\|g\left(x_{k+1}\right)\right\| \leq \sqrt{\left(1-\delta \bar{\alpha}^{2} \frac{1}{2 \bar{d}}\right)}\left\|g\left(x_{k}\right)\right\| .
$$

Inequality (3.16) and inductive process yields

$$
\left\|g\left(x_{k}\right)\right\| \leq \mu^{k}\left\|g\left(x_{0}\right)\right\|
$$

where $\mu=\sqrt{\left(1-\delta \bar{\alpha}^{2} \frac{1}{2 \bar{d}}\right)}<1$. Using (3.1) together with (3.17) we have

$$
\left\|x_{k}-x^{*}\right\| \leq \mu^{k} \frac{\left\|g\left(x_{0}\right)\right\|}{m}
$$

Thus, (3.15) holds with $C=\frac{\left\|g\left(x_{0}\right)\right\|}{m}$. This means that Algorithm 1 converges R-linearly.

\section{NUMERICAL EXPERIMENTS}

In this section we report the results obtained with a preliminary MATLAB implementation of the proposed algorithm on the solution of some selected test problems. The set of the problems is made of ten almost separable nonlinear equations and can be found in the Appendix A. The detailed numerical results of this section can be found in Appendix B. Computations were carried out on an 8.00 GB RAM Intel Core i7 personal computer at $2.30 \mathrm{GHz}$. A failure is reported (denoted by ' $F$ '), if the number of iterations is greater than 1000 . We used five different dimension with ten different initial points as follows:

- dimensions: $n=1000,5000,10000,50000,100000$.

- initial points: $x_{0}^{1}=(1, \ldots, 1)^{T}, \quad x_{0}^{2}=(0.1, \ldots, 0.1)^{T}, \quad x_{0}^{3}=\left(\frac{1}{2}, \ldots, \frac{1}{2^{n}}\right)^{T}, \quad x_{0}^{4}=\left(1-\frac{1}{n}, 1-\frac{2}{n}, \ldots, 0\right)^{T}$, $x_{0}^{5}=\left(0, \frac{1}{n}, \frac{2}{n}, \ldots, \frac{n-1}{n}\right)^{T}, \quad x_{0}^{6}=\left(1, \frac{1}{2}, \ldots, \frac{1}{n}\right)^{T}, \quad x_{0}^{7}=\left(\frac{n-1}{n}, \frac{n-2}{n}, \ldots, 0\right)^{T}, \quad x_{0}^{8}=\left(\frac{1}{n}, \frac{2}{n}, \ldots, 1\right)^{T}, x_{0}^{9}=$ $(10,10, \ldots, 10)^{T}$ and $x_{0}^{10}=\operatorname{rand}(n, 1)$. Here, $\operatorname{rand}(n, 1)$ means the initial point is chosen randomly from the interval $(0,1)$. 
TABLE 1 . Winners with respect to \#iter, \#fval and time.

\begin{tabular}{cccc}
\hline \hline Method/Metric & dfnwt & dfsane & msgp \\
\hline \#iter & 329 & 291 & 75 \\
\#fval & 353 & 309 & 30 \\
time & 103 & 366 & 24 \\
\hline
\end{tabular}

We compared Algorithm 1 (dfnwt) with similar algorithms in the literature, namely, dfsane algorithm by La Cruz et al. [13] and msgp algorithm by Yu et al. [28]. For all algorithms, we used the stopping criterion

$$
\left\|g\left(x_{k}\right)\right\| \leq 10^{-6} .
$$

We implemented dfnwt algorithm using the following parameters: $\rho=0.5, \delta=0.0001, \underline{d}=10^{-10}, \bar{d}=$ $10^{10}$ and $\varpi_{k}=\frac{1}{e^{k^{2}}}, \quad k>0$. For dfsane and msgp algorithms, the parameters chosen are from references [13] and [28], respectively.

In Tables B.1-B.10 of Appendix B, we reported the number of iterations (\#iter), the number of function evaluations (\#fval), the CPU time in seconds (time) and the norm of the residual at the termination point (Fnorm), for all the ten tested problems. In Table B.1, dfnwt has the least \#iter and \# fval in all the problems. However, there was a tie between dfnwt and df sane in Tables B.2-B.5, B.7 and B.8 except for the the initial point $x_{0}^{9}$ and some some few cases in Tables B.7 and B.8. In Table B.6, dfsane has the best performance in terms of \#iter and \#fval except for some few cases where dfnwt performs better. The algorithm dfnwt has recorded 17 failures in Table B.9, however, it outperforms dfsane and msgp algorithms in the remaining cases. Lastly, in Table B.10, unlike dfsane and msgp, dfnwt managed to solve almost all the problems. However, for the few cases where msgp solved a problem, it has the least \#iter and \#fval. In addition, the summary of Tables B.1-B.10 is reported in Table 1.

To visualize the numerical behaviour of the algorithms, we plotted three figures using the popular Dolan and Moré [4] performance profile based on the \#iter, \#fval and CPU time metrics. In Figure 1, we compare the performance of the dfnwt algorithm with the dfsane algorithm and the msgp algorithm with respect to \#iter metric. Figure 1 shows that dfnwt performs better than msgp and dfsane having almost $70 \%$ success. In Figure 2, the performance of the three algorithms was tested based on \#fval metric. The figure shows that dfnwt performs better than msgp and dfsane having over $70 \%$ success. Figure 3 shows that df sane is faster than dfnwt and msgp for the fraction of $\tau \leq 4$. However, for $\tau>4$, dfnwt is faster than msgp and dfsane. Based on the performed experiments, we observe that, the good performance of the dfnwt algorithm may be due to the diagonal approximation of the Jacobian matrix associated with the search direction. Similar argument applies to the msgp algorithm.

\section{Conclusions}

We have presented, analyzed, and implemented a derivative-free quasi-Newton-type algorithm for solving nonlinear systems of equations with separable functions (dfnwt). Different from the existing algorithms such as dfsane algorithm that approximate the Jacobian of $g$ using a scalar multiple of identity at each iteration, the proposed dfnwt algorithm uses a diagonal matrix in a quasi-Newton manner for such approximations. Among the attractive feature of the presented algorithm is that it does not require gradient or approximation of the gradient for its implementation, this makes it more suitable for large-scale separable problems. Furthermore, the global and R-linear convergence of the sequence generated by dfnwt algorithm is obtained. Based on the numerical results presented, the proposed dfnwt compete with the well-known and efficient algorithm for solving nonlinear equations, that is, dfsane. This good efficiency of the dfnwt algorithm is due to the additional information obtained from the diagonal matrix used for the approximation of the Jacobian of the problems. 


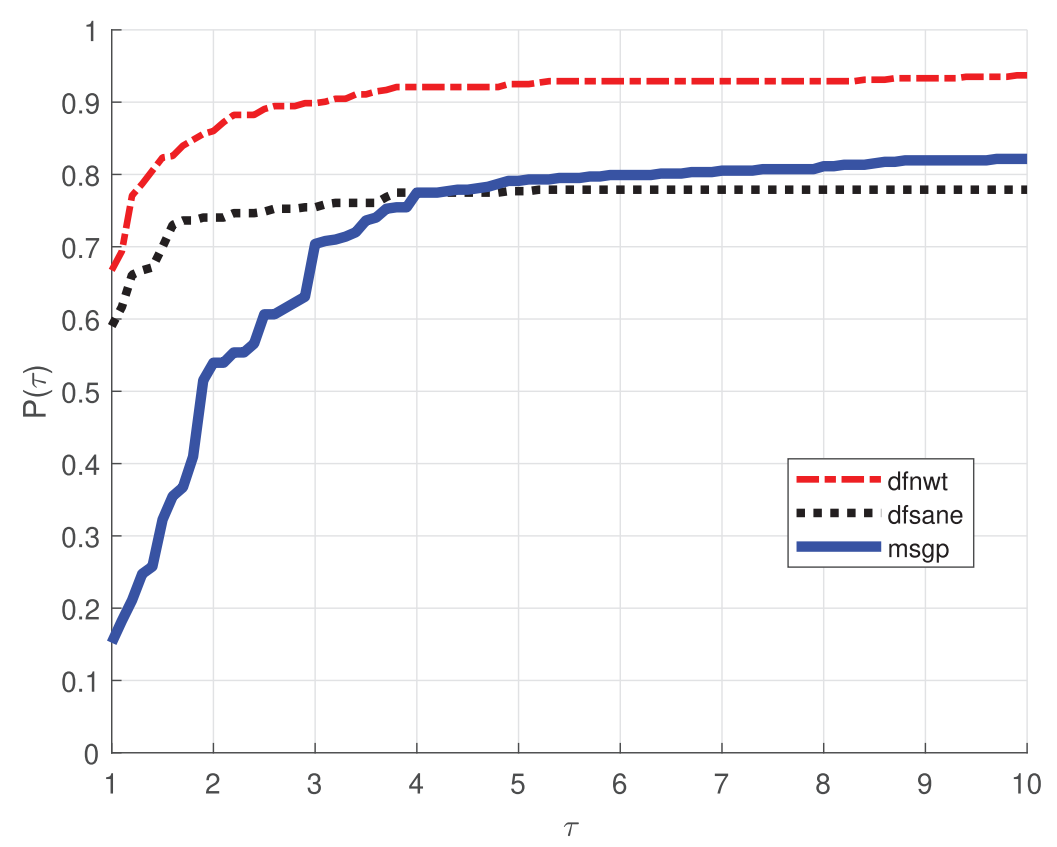

Figure 1. Dolan and Moré performance profile with respect to number of iterations.

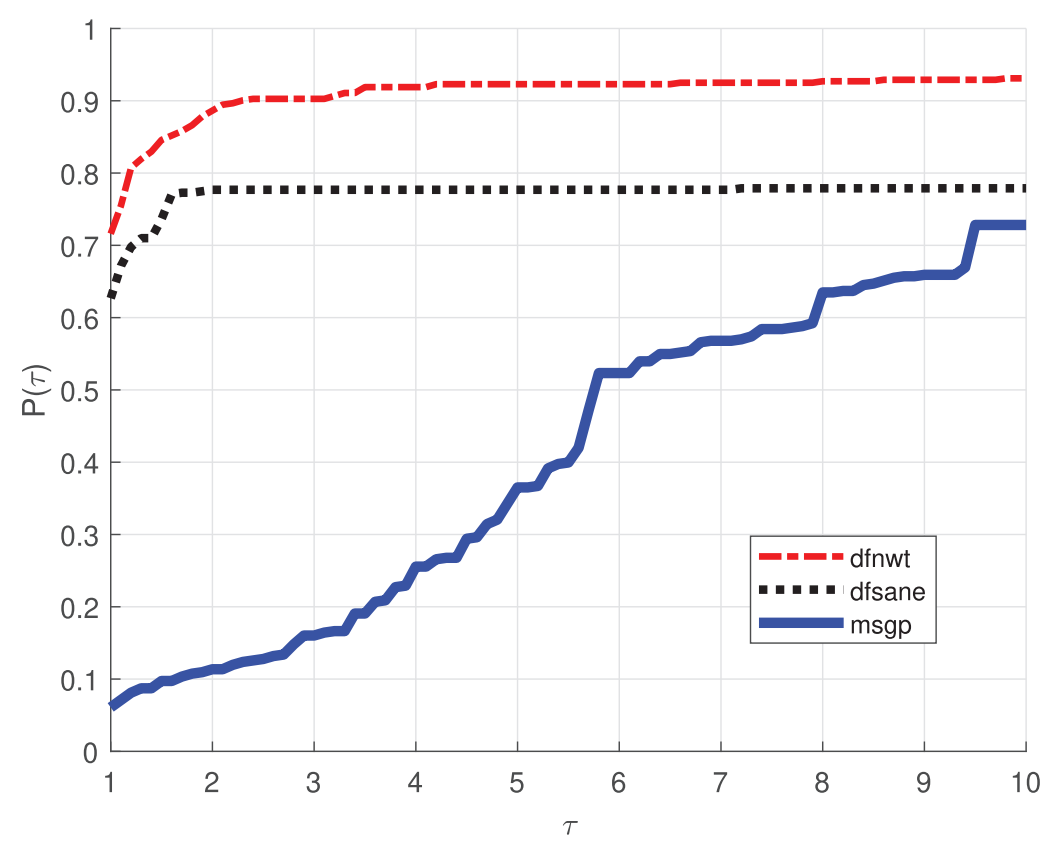

FigURE 2. Dolan and Moré performance profile with respect to number of function evaluations. 


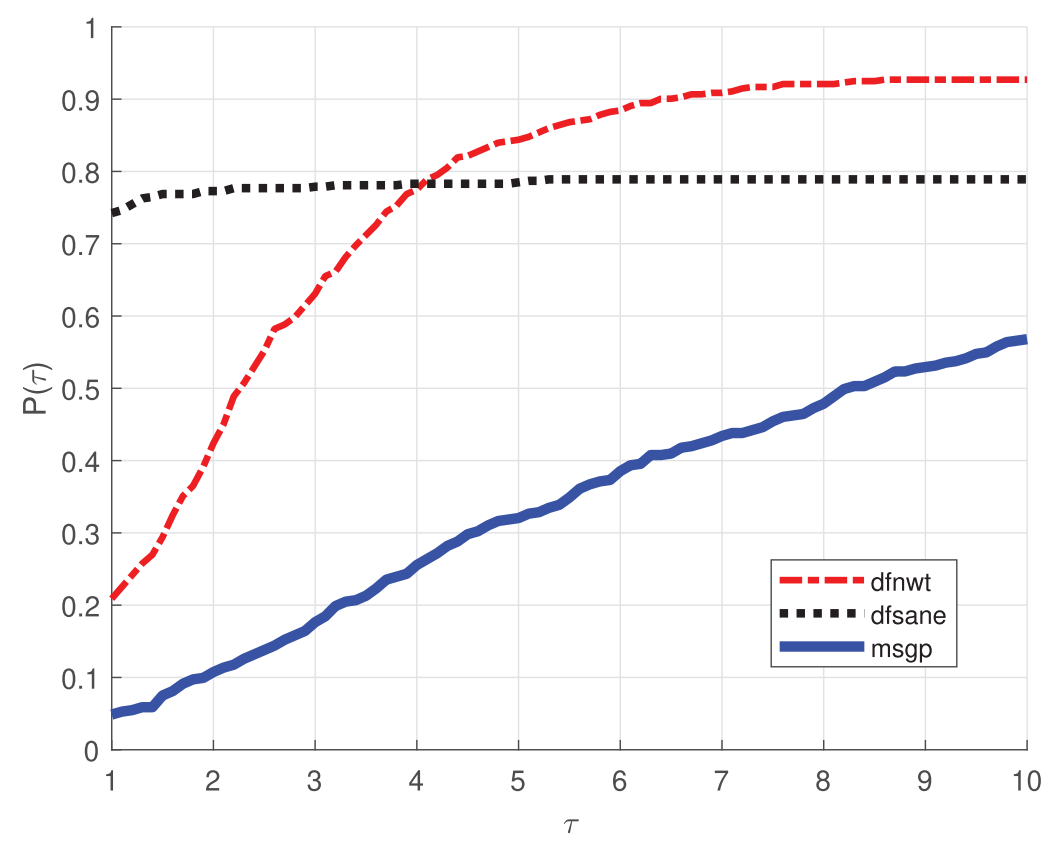

FiguRE 3. Dolan and Moré performance profile with respect to CPU time.

Investigation on the better approximation that exploits the structure of the problem and extensive numerical experiments that will unveil the effectiveness of the approach will be an interesting topic for future research.

\section{Appendix A. List of test problems}

We listed below the details of the test problems used in Section 4 where $g=\left(g_{1}, g_{2}, \ldots, g_{n}\right)^{T}$.

Problem 1: Modified exponential function [12]

$$
\begin{aligned}
g_{1}(x) & =e^{x_{1}}-1 \\
g_{i}(x) & =e^{x_{i}}+x_{i}-1, \quad i=2,3 \ldots, n-1 .
\end{aligned}
$$

Problem 2: Logarithmic function [12]

$$
g_{i}\left(x_{i}\right)=\log \left(x_{i}+1\right)-\frac{x_{i}}{n}, \quad i=1,2, \ldots, n .
$$

Problem 3: Strictly convex function I [12]

$$
g_{i}(x)=e^{x_{i}}-1, \quad i=1,2, \ldots, n .
$$

$\underline{\text { Problem 4: }}$ Modified strictly convex function II [12]

$$
g_{i}(x)=\left(\frac{i}{n+1}\right) e^{x_{i}}-1, \quad i=1,2, \ldots, n .
$$


Problem 5: Tridiagonal exponential function [1]

$$
\begin{aligned}
g_{1}(x) & =x_{1}-e^{\cos \left(h\left(x_{1}+x_{2}\right)\right)} \\
g_{i}(x) & =x_{i}-e^{\cos \left(h\left(x_{i-1}+x_{i}+x_{i+1}\right)\right)}, \quad i=2, \ldots, n-1, \\
g_{n}(x) & =x_{n}-e^{\cos \left(h\left(x_{n-1}+x_{n}\right)\right)}, \\
h & =\frac{1}{n+1} .
\end{aligned}
$$

Problem 6: Gradient of engval function [15]

$$
\begin{aligned}
g_{1}(x) & =x_{1}\left(x_{1}^{2}+x_{2}^{2}\right)-1 \\
g_{i}(x) & =x_{i}\left(x_{i-1}^{2}+2 x_{i}^{2}+x_{i+1}^{2}\right)-1, \quad 2 \leq i \leq n-1 \\
g_{n}(x) & =x_{n}\left(x_{n-1}^{2}+x_{n}^{2}\right) .
\end{aligned}
$$

Problem 7: Chandrasekhar H-equation [9]

$$
g_{i}(x)=x_{i}-\left(1-\frac{c}{2 n} \sum_{j=1}^{n} \frac{\delta_{i} x_{j}}{\delta_{i}+\delta_{j}}\right)^{-1}, \quad c=0.9, \quad \delta_{i}=\frac{i-0.5}{n}, \quad i=1,2, \ldots, n .
$$

Problem 8: Modified problem 3.34 in [16]

$$
\begin{aligned}
& g_{i}(x)=x_{i}-\frac{x_{i+1}^{3}}{100}, \quad 1 \leq i \leq n-1 \\
& g_{n}(x)=x_{n}-\frac{x_{n}^{3}}{100} .
\end{aligned}
$$

Problem 9: Trigonometric function [30]

$$
g_{i}(x)=2\left(n+i\left(1-\cos x_{i}\right)-\sin x_{i}-\sum_{j=1}^{n} \cos x_{j}\right)\left(2 \sin x_{i}-\cos x_{i}\right), \text { for } i=1,2,3, \ldots, n .
$$

Problem 10: Troesch problem [12]

$$
\begin{aligned}
& g_{1}(x)=2 x_{1}+10 \frac{\sinh \left(10 x_{1}\right)}{(n+1)^{2}}-x_{2} \\
& g_{i}(x)=2 x_{i}+10 \frac{\sinh \left(10 x_{i}\right)}{(n+1)^{2}}-x_{i-1}-x_{i+1}, \quad 2 \leq i \leq n-1 \\
& g_{n}(x)=2 x_{n}+10 \frac{\sinh \left(10 x_{n}\right)}{(n+1)^{2}}-x_{n-1}-1 .
\end{aligned}
$$

\section{Appendix B. Table of Numerical Experiments}

Below is the details of the numerical experiments conducted in Section 4. 
TABle B.1. Numerical results for dfnwt, dfsane and msgp for Problem 1 with given initial points and dimensions.

\begin{tabular}{|c|c|c|c|c|c|c|c|c|c|c|c|c|c|}
\hline \multirow[b]{2}{*}{ Dimension } & \multirow[b]{2}{*}{$x_{0}$} & \multicolumn{4}{|c|}{ dfnwt } & \multicolumn{4}{|c|}{ dfsane } & \multicolumn{4}{|c|}{ msgp } \\
\hline & & \#iter & \#fval & time & Fnorm & \#iter & \#fval & time & Fnorm & \#iter & \#fval & time & Fnorm \\
\hline \multirow{9}{*}{1000} & $x_{0}^{1}$ & 7 & 7 & 0.0144 & $1.76 \mathrm{E}-08$ & 11 & 11 & 0.0303 & $1.33 \mathrm{E}-08$ & 8 & 25 & 0.0944 & $1.16 \mathrm{E}-07$ \\
\hline & $x_{0}^{3}$ & 5 & 5 & 0.0046 & $6.23 \mathrm{E}-08$ & 8 & 8 & 0.0099 & $1.51 \mathrm{E}-07$ & 9 & 28 & 0.1310 & $4.04 \mathrm{E}-08$ \\
\hline & $x_{0}^{4}$ & 7 & 7 & 0.0082 & $1.38 \mathrm{E}-08$ & 10 & 10 & 0.0079 & $8.47 \mathrm{E}-07$ & 11 & 34 & 0.0160 & $1.75 \mathrm{E}-08$ \\
\hline & $x_{0}^{5}$ & 7 & 7 & 0.0068 & $1.44 \mathrm{E}-09$ & 7 & 7 & 0.0262 & $5.15 \mathrm{E}-11$ & 10 & 31 & 0.0216 & $1.18 \mathrm{E}-07$ \\
\hline & $x_{0}^{6}$ & 7 & 7 & 0.0070 & $1.43 \mathrm{E}-08$ & 10 & 10 & 0.0075 & $1.04 \mathrm{E}-08$ & 12 & 37 & 0.0152 & $8.39 \mathrm{E}-09$ \\
\hline & $x_{0}^{8}$ & 7 & 7 & 0.0049 & $1.47 \mathrm{E}-09$ & 7 & 7 & 0.0045 & $5.03 \mathrm{E}-09$ & 10 & 31 & 0.0130 & $1.22 \mathrm{E}-07$ \\
\hline & $x_{0}^{9}$ & $\mathrm{~F}$ & $\mathrm{~F}$ & $\mathrm{~F}$ & $\mathrm{~F}$ & $\mathrm{~F}$ & $\mathrm{~F}$ & $\mathrm{~F}$ & $\mathrm{~F}$ & 15 & 46 & 0.0368 & $2.17 \mathrm{E}-07$ \\
\hline & $x_{0}^{10}$ & 7 & 7 & 0.0118 & $1.31 \mathrm{E}-09$ & 10 & 10 & 0.0055 & $2.13 \mathrm{E}-08$ & 10 & 31 & 0.0123 & $1.19 \mathrm{E}-07$ \\
\hline & $x_{0}^{1}$ & 7 & 7 & 0.0332 & $2.71 \mathrm{E}-08$ & 11 & 11 & 0.0132 & $6.70 \mathrm{E}-08$ & 8 & 25 & 0.0385 & $6.68 \mathrm{E}-07$ \\
\hline \multirow{11}{*}{5000} & $x_{0}^{2}$ & 5 & 5 & 0.0188 & $1.09 \mathrm{E}-10$ & 6 & 6 & 0.0105 & $8.53 \mathrm{E}-08$ & 6 & 19 & 0.0369 & $1.05 \mathrm{E}-08$ \\
\hline & $x_{0}^{3}$ & 5 & 5 & 0.0153 & $6.23 \mathrm{E}-08$ & 8 & 8 & 0.0138 & $1.51 \mathrm{E}-07$ & 9 & 28 & 1.5317 & $4.04 \mathrm{E}-08$ \\
\hline & $x_{0}^{4}$ & 7 & 7 & 0.1608 & $1.45 \mathrm{E}-08$ & 10 & 10 & 0.0086 & $5.96 \mathrm{E}-07$ & 11 & 34 & 0.0477 & $4.05 \mathrm{E}-07$ \\
\hline & $x_{0}^{5}$ & 7 & 7 & 0.0141 & $3.24 \mathrm{E}-09$ & 7 & 7 & 0.0174 & $1.16 \mathrm{E}-10$ & 10 & 31 & 0.0569 & $2.68 \mathrm{E}-07$ \\
\hline & $x_{0}^{7}$ & 7 & 7 & 0.0129 & $1.45 \mathrm{E}-08$ & 10 & 10 & 0.0187 & $5.96 \mathrm{E}-07$ & 11 & 34 & 0.0353 & $4.05 \mathrm{E}-07$ \\
\hline & $x_{0}^{8}$ & 7 & 7 & 0.0124 & $3.26 \mathrm{E}-09$ & 7 & 7 & 0.0102 & $2.33 \mathrm{E}-10$ & 10 & 31 & 0.0385 & $2.70 \mathrm{E}-07$ \\
\hline & $x_{0}^{9}$ & $\mathrm{~F}$ & $\mathrm{~F}$ & $\mathrm{~F}$ & $\mathrm{~F}$ & $\mathrm{~F}$ & $\mathrm{~F}$ & $\mathrm{~F}$ & $\mathrm{~F}$ & 15 & 46 & 0.0787 & $1.85 \mathrm{E}-07$ \\
\hline & $x_{0}^{10}$ & 7 & 7 & 0.0244 & $3.14 \mathrm{E}-09$ & 8 & 8 & 0.0114 & $5.41 \mathrm{E}-07$ & 10 & 31 & 0.0629 & $2.90 \mathrm{E}-07$ \\
\hline & $x_{0}^{1}$ & 7 & 7 & 0.0498 & $3.55 \mathrm{E}-08$ & 11 & 11 & 0.0247 & $4.37 \mathrm{E}-08$ & 8 & 25 & 0.0614 & $7.40 \mathrm{E}-07$ \\
\hline & $x_{0}^{2}$ & 5 & 5 & 0.0381 & $1.54 \mathrm{E}-10$ & 6 & 6 & 0.0108 & $5.09 \mathrm{E}-08$ & 6 & 19 & 0.0379 & $1.06 \mathrm{E}-08$ \\
\hline & $x_{0}^{3}$ & 5 & 5 & 0.0403 & $6.23 \mathrm{E}-08$ & 8 & 8 & 0.0133 & $1.51 \mathrm{E}-07$ & 9 & 28 & 2.6461 & $4.04 \mathrm{E}-08$ \\
\hline \multirow{7}{*}{10000} & $x_{0}^{4}$ & 7 & 7 & 0.0606 & $1.49 \mathrm{E}-08$ & 10 & 10 & 0.0124 & $5.05 \mathrm{E}-07$ & 11 & 34 & 0.0767 & $8.47 \mathrm{E}-07$ \\
\hline & $x_{0}^{5}$ & 7 & 7 & 0.0304 & $4.59 \mathrm{E}-09$ & 7 & 7 & 0.0084 & $1.65 \mathrm{E}-10$ & 10 & 31 & 0.0881 & $3.80 \mathrm{E}-07$ \\
\hline & $x_{0}^{6}$ & 7 & 7 & 0.0221 & $1.43 \mathrm{E}-08$ & 10 & 10 & 0.0103 & $1.04 \mathrm{E}-08$ & 12 & 37 & 0.0773 & $1.13 \mathrm{E}-08$ \\
\hline & $x_{0}^{7}$ & 7 & 7 & 0.0315 & $1.49 \mathrm{E}-08$ & 10 & 10 & 0.0140 & $5.05 \mathrm{E}-07$ & 11 & 34 & 0.0667 & $8.47 \mathrm{E}-07$ \\
\hline & $x_{0}^{8}$ & 7 & 7 & 0.0513 & $4.61 \mathrm{E}-09$ & 7 & 7 & 0.0155 & $1.72 \mathrm{E}-10$ & 10 & 31 & 0.0602 & $3.81 \mathrm{E}-07$ \\
\hline & $x_{0}^{9}$ & $\mathrm{~F}$ & $\mathrm{~F}$ & $\mathrm{~F}$ & $\mathrm{~F}$ & $\mathrm{~F}$ & $\mathrm{~F}$ & $\mathrm{~F}$ & $\mathrm{~F}$ & 15 & 46 & 0.1247 & $1.70 \mathrm{E}-07$ \\
\hline & $x_{0}^{10}$ & 7 & 7 & 0.0746 & $4.62 \mathrm{E}-09$ & 10 & 10 & 0.0264 & $4.76 \mathrm{E}-07$ & 10 & 31 & 0.1081 & $3.66 \mathrm{E}-07$ \\
\hline \multirow{11}{*}{50000} & $x_{0}^{1}$ & 7 & 7 & 0.1347 & $7.41 \mathrm{E}-08$ & 11 & 11 & 0.0822 & $2.59 \mathrm{E}-08$ & 8 & 25 & 0.2588 & $4.02 \mathrm{E}-07$ \\
\hline & $x_{0}^{2}$ & 5 & 5 & 0.1261 & $3.44 \mathrm{E}-10$ & 6 & 6 & 0.0392 & $2.23 \mathrm{E}-07$ & 6 & 19 & 0.1970 & $1.26 \mathrm{E}-08$ \\
\hline & $x_{0}^{3}$ & 5 & 5 & 0.0542 & $6.23 \mathrm{E}-08$ & 8 & 8 & 0.0445 & $1.51 \mathrm{E}-07$ & 9 & 28 & 20.1184 & $4.04 \mathrm{E}-08$ \\
\hline & $x_{0}^{6}$ & 7 & 7 & 0.1411 & $1.43 \mathrm{E}-08$ & 10 & 10 & 0.0903 & $1.04 \mathrm{E}-08$ & 12 & 37 & 0.2629 & $1.16 \mathrm{E}-08$ \\
\hline & $x_{0}^{7}$ & 7 & 7 & 0.1466 & $1.76 \mathrm{E}-08$ & 11 & 11 & 0.0644 & $8.95 \mathrm{E}-09$ & 12 & 37 & 0.3564 & $9.92 \mathrm{E}-09$ \\
\hline & $x_{0}^{8}$ & 7 & 7 & 0.2467 & $1.03 \mathrm{E}-08$ & 7 & 7 & 0.0452 & $3.69 \mathrm{E}-10$ & 10 & 31 & 0.3816 & $8.51 \mathrm{E}-07$ \\
\hline & $x_{0}^{9}$ & $\mathrm{~F}$ & $\mathrm{~F}$ & $\mathrm{~F}$ & $\mathrm{~F}$ & $\mathrm{~F}$ & $\mathrm{~F}$ & $\mathrm{~F}$ & $\mathrm{~F}$ & 18 & 55 & 0.6111 & $2.52 \mathrm{E}-08$ \\
\hline & $x_{0}^{10}$ & 7 & 7 & 0.2109 & $1.02 \mathrm{E}-08$ & 8 & 8 & 0.0685 & $4.48 \mathrm{E}-07$ & 10 & 31 & 0.2158 & $8.19 \mathrm{E}-07$ \\
\hline & $x_{0}^{1}$ & 7 & 7 & 0.3991 & $1.04 \mathrm{E}-07$ & 11 & 11 & 0.0844 & $3.33 \mathrm{E}-08$ & 8 & 25 & 0.3365 & $3.34 \mathrm{E}-07$ \\
\hline & $x_{0}^{2}$ & 5 & 5 & 0.1823 & $4.87 \mathrm{E}-10$ & 6 & 6 & 0.0503 & $5.42 \mathrm{E}-07$ & 6 & 19 & 0.4366 & $1.43 \mathrm{E}-08$ \\
\hline & $x_{0}^{3}$ & 5 & 5 & 0.1929 & $6.23 \mathrm{E}-08$ & 8 & 8 & 0.1260 & $1.51 \mathrm{E}-07$ & 9 & 28 & 66.4908 & $4.04 \mathrm{E}-08$ \\
\hline \multirow{7}{*}{100000} & $x_{0}^{4}$ & 7 & 7 & 0.4219 & $2.04 \mathrm{E}-08$ & 11 & 11 & 0.1170 & $1.87 \mathrm{E}-08$ & 11 & 34 & 0.7349 & $6.45 \mathrm{E}-07$ \\
\hline & $x_{0}^{5}$ & 7 & 7 & 0.4051 & $1.45 \mathrm{E}-08$ & 7 & 7 & 0.1085 & $5.21 \mathrm{E}-10$ & 11 & 34 & 0.7134 & $5.98 \mathrm{E}-09$ \\
\hline & $x_{0}^{6}$ & 7 & 7 & 0.3407 & $1.43 \mathrm{E}-08$ & 10 & 10 & 0.0876 & $1.04 \mathrm{E}-08$ & 12 & 37 & 0.6490 & $1.16 \mathrm{E}-08$ \\
\hline & $x_{0}^{7}$ & 7 & 7 & 0.3645 & $2.04 \mathrm{E}-08$ & 11 & 11 & 0.0891 & $1.87 \mathrm{E}-08$ & 11 & 34 & 0.7292 & $6.45 \mathrm{E}-07$ \\
\hline & $x_{0}^{8}$ & 7 & 7 & 0.3735 & $1.45 \mathrm{E}-08$ & 7 & 7 & 0.0885 & $5.21 \mathrm{E}-10$ & 11 & 34 & 0.6609 & $5.99 \mathrm{E}-09$ \\
\hline & $x_{0}^{9}$ & $\mathrm{~F}$ & $\mathrm{~F}$ & $\mathrm{~F}$ & $\mathrm{~F}$ & $\mathrm{~F}$ & $\mathrm{~F}$ & $\mathrm{~F}$ & $\mathrm{~F}$ & 18 & 55 & 1.2723 & $2.82 \mathrm{E}-08$ \\
\hline & $x_{0}^{10}$ & 7 & 7 & 0.4249 & $1.46 \mathrm{E}-08$ & 11 & 11 & 0.1426 & $3.83 \mathrm{E}-09$ & 11 & 34 & 0.7735 & $5.87 \mathrm{E}-09$ \\
\hline
\end{tabular}


TABle B.2. Numerical results for dfnwt, dfsane and msgp for Problem 2 with given initial points and dimensions.

\begin{tabular}{|c|c|c|c|c|c|c|c|c|c|c|c|c|c|}
\hline \multirow[b]{2}{*}{ Dimension } & \multirow[b]{2}{*}{$x_{0}$} & \multicolumn{4}{|c|}{ dfnwt } & \multicolumn{4}{|c|}{ dfsane } & \multicolumn{4}{|c|}{ msgp } \\
\hline & & \#iter & \#fval & time & Fnorm & \#iter & \#fval & time & Fnorm & \#iter & \#fval & time & Fnorm \\
\hline \multirow{11}{*}{1000} & $x_{0}^{1}$ & 6 & 6 & 0.0097 & $2.58 \mathrm{E}-07$ & 6 & 6 & 0.0054 & $2.58 \mathrm{E}-07$ & 7 & 22 & 0.0172 & $7.57 \mathrm{E}-07$ \\
\hline & $x_{0}^{2}$ & 4 & 4 & 0.0092 & $2.11 \mathrm{E}-09$ & 4 & 4 & 0.0043 & $2.11 \mathrm{E}-09$ & 5 & 16 & 0.0098 & $4.79 \mathrm{E}-08$ \\
\hline & $x_{0}^{3}$ & 5 & 5 & 0.0132 & $5.77 \mathrm{E}-09$ & 5 & 5 & 0.0062 & 2.07E-09 & 9 & 28 & 0.0774 & $4.19 \mathrm{E}-07$ \\
\hline & $x_{0}^{4}$ & 6 & 6 & 0.0121 & $4.29 \mathrm{E}-08$ & 6 & 6 & 0.0038 & $1.40 \mathrm{E}-09$ & 11 & 34 & 0.0121 & $2.76 \mathrm{E}-08$ \\
\hline & $x_{0}^{5}$ & 6 & 6 & 0.0086 & $4.29 \mathrm{E}-08$ & 6 & 6 & 0.0042 & $1.40 \mathrm{E}-09$ & 11 & 34 & 0.0205 & $2.76 \mathrm{E}-08$ \\
\hline & $x_{0}^{6}$ & 6 & 6 & 0.0059 & $8.17 \mathrm{E}-09$ & 5 & 5 & 0.0025 & $5.79 \mathrm{E}-07$ & 11 & 34 & 0.0202 & $1.69 \mathrm{E}-08$ \\
\hline & $x_{0}^{8}$ & 6 & 6 & 0.0046 & $4.37 \mathrm{E}-08$ & 6 & 6 & 0.0057 & $1.43 \mathrm{E}-09$ & 11 & 34 & 0.0181 & $2.73 \mathrm{E}-08$ \\
\hline & $x_{0}^{9}$ & $\mathrm{~F}$ & $\mathrm{~F}$ & $\mathrm{~F}$ & $\mathrm{~F}$ & 10 & 16 & 0.0144 & 7.19E-09 & $\mathrm{F}$ & $\mathrm{F}$ & F & $\mathrm{F}$ \\
\hline & $x_{0}^{10}$ & 6 & 6 & 0.0075 & $4.13 \mathrm{E}-08$ & 6 & 6 & 0.0061 & $1.21 \mathrm{E}-09$ & 11 & 34 & 0.0067 & $2.35 \mathrm{E}-08$ \\
\hline & $x_{0}^{1}$ & 6 & 6 & 0.0143 & $5.60 \mathrm{E}-07$ & 6 & 6 & 0.0098 & $5.60 \mathrm{E}-07$ & 8 & 25 & 0.0366 & $1.71 \mathrm{E}-08$ \\
\hline & $x_{0}^{2}$ & 4 & 4 & 0.0102 & $4.46 \mathrm{E}-09$ & 4 & 4 & 0.0101 & $4.46 \mathrm{E}-09$ & 5 & 16 & 0.0246 & $1.06 \mathrm{E}-07$ \\
\hline \multirow{9}{*}{5000} & $x_{0}^{3}$ & 5 & 5 & 0.0083 & $5.62 \mathrm{E}-09$ & 5 & 5 & 0.0080 & $2.02 \mathrm{E}-09$ & 9 & 28 & 1.2953 & $4.30 \mathrm{E}-07$ \\
\hline & $x_{0}^{4}$ & 6 & 6 & 0.0362 & $9.36 \mathrm{E}-08$ & 6 & 6 & 0.0085 & $3.06 \mathrm{E}-09$ & 11 & 34 & 0.0985 & $6.33 \mathrm{E}-08$ \\
\hline & $x_{0}^{5}$ & 6 & 6 & 0.0373 & $9.36 \mathrm{E}-08$ & 6 & 6 & 0.0151 & $3.06 \mathrm{E}-09$ & 11 & 34 & 0.1229 & $6.33 \mathrm{E}-08$ \\
\hline & $x_{0}^{8}$ & 6 & 6 & 0.0221 & $9.40 \mathrm{E}-08$ & 6 & 6 & 0.0109 & 3.07E-09 & 11 & 34 & 0.0678 & $6.31 \mathrm{E}-08$ \\
\hline & $x_{0}^{9}$ & $\mathrm{~F}$ & $\mathrm{~F}$ & $\mathrm{~F}$ & $\mathrm{~F}$ & 10 & 16 & 0.0236 & $2.09 \mathrm{E}-08$ & 9 & 28 & 0.0658 & $9.66 \mathrm{E}-08$ \\
\hline & $x_{0}^{10}$ & 6 & 6 & 0.0178 & $9.61 \mathrm{E}-08$ & 6 & 6 & 0.0079 & $2.98 \mathrm{E}-09$ & 11 & 34 & 0.0623 & $6.52 \mathrm{E}-08$ \\
\hline & $x_{0}^{1}$ & 6 & 6 & 0.0702 & $7.88 \mathrm{E}-07$ & 6 & 6 & 0.0103 & $7.88 \mathrm{E}-07$ & 8 & 25 & 0.0613 & $2.43 \mathrm{E}-08$ \\
\hline & $x_{0}^{2}$ & 4 & 4 & 0.0288 & $6.27 \mathrm{E}-09$ & 4 & 4 & 0.0170 & $6.27 \mathrm{E}-09$ & 5 & 16 & 0.1003 & $1.50 \mathrm{E}-07$ \\
\hline & $\begin{array}{l}{ }_{0}^{0} \\
x_{0}^{3}\end{array}$ & 5 & 5 & 0.0328 & $5.60 \mathrm{E}-09$ & 5 & 5 & 0.0152 & $2.02 \mathrm{E}-09$ & 9 & 28 & 2.7424 & $4.31 \mathrm{E}-07$ \\
\hline \multirow{7}{*}{10000} & $x_{0}^{4}$ & 6 & 6 & 0.0397 & $1.32 \mathrm{E}-07$ & 6 & 6 & 0.0131 & $4.32 \mathrm{E}-09$ & 11 & 34 & 0.1765 & $8.97 \mathrm{E}-08$ \\
\hline & $x_{0}^{5}$ & 6 & 6 & 0.0270 & $1.32 \mathrm{E}-07$ & 6 & 6 & 0.0112 & $4.32 \mathrm{E}-09$ & 11 & 34 & 0.1630 & $8.97 \mathrm{E}-08$ \\
\hline & $x_{0}^{6}$ & 6 & 6 & 0.0333 & $7.88 \mathrm{E}-09$ & 5 & 5 & 0.0159 & $5.67 \mathrm{E}-07$ & 11 & 34 & 0.1345 & $1.68 \mathrm{E}-08$ \\
\hline & $x_{0}^{7}$ & 6 & 6 & 0.0438 & $1.32 \mathrm{E}-07$ & 6 & 6 & 0.0202 & $4.32 \mathrm{E}-09$ & 11 & 34 & 0.1521 & $8.97 \mathrm{E}-08$ \\
\hline & $x_{0}^{8}$ & 6 & 6 & 0.0557 & $1.32 \mathrm{E}-07$ & 6 & 6 & 0.0228 & $4.32 \mathrm{E}-09$ & 11 & 34 & 0.0949 & $8.96 \mathrm{E}-08$ \\
\hline & $x_{0}^{9}$ & $\mathrm{~F}$ & $\mathrm{~F}$ & $\mathrm{~F}$ & $\mathrm{~F}$ & 10 & 16 & 0.0381 & $3.04 \mathrm{E}-08$ & 9 & 28 & 0.1200 & $1.37 \mathrm{E}-07$ \\
\hline & $x_{0}^{10}$ & 6 & 6 & 0.0449 & $1.31 \mathrm{E}-07$ & 6 & 6 & 0.0187 & $4.16 \mathrm{E}-09$ & 11 & 34 & 0.1252 & $9.24 \mathrm{E}-08$ \\
\hline \multirow{11}{*}{50000} & $x_{0}^{1}$ & 7 & 7 & 0.2191 & $1.08 \mathrm{E}-11$ & 7 & 7 & 0.0473 & $1.08 \mathrm{E}-11$ & 8 & 25 & 0.4062 & $5.44 \mathrm{E}-08$ \\
\hline & $x_{0}^{2}$ & 4 & 4 & 0.0869 & $1.39 \mathrm{E}-08$ & 4 & 4 & 0.0269 & $1.39 \mathrm{E}-08$ & 5 & 16 & 0.2628 & $3.34 \mathrm{E}-07$ \\
\hline & $x_{0}^{3}$ & 5 & 5 & 0.0856 & $5.59 \mathrm{E}-09$ & 5 & 5 & 0.0302 & $2.01 \mathrm{E}-09$ & 9 & 28 & 20.5273 & $4.32 \mathrm{E}-07$ \\
\hline & $x_{0}^{4}$ & 6 & 6 & 0.1248 & $2.94 \mathrm{E}-07$ & 6 & 6 & 0.0305 & $9.63 \mathrm{E}-09$ & 11 & 34 & 0.5027 & $2.01 \mathrm{E}-07$ \\
\hline & $x_{0}^{7}$ & 6 & 6 & 0.2749 & $2.94 \mathrm{E}-07$ & 6 & 6 & 0.0964 & $9.63 \mathrm{E}-09$ & 11 & 34 & 0.5028 & $2.01 \mathrm{E}-07$ \\
\hline & $x_{0}^{8}$ & 6 & 6 & 0.1795 & $2.95 \mathrm{E}-07$ & 6 & 6 & 0.0522 & $9.63 \mathrm{E}-09$ & 11 & 34 & 0.4857 & $2.01 \mathrm{E}-07$ \\
\hline & $x_{0}^{9}$ & $\mathrm{~F}$ & $\mathrm{~F}$ & $\mathrm{~F}$ & $\mathrm{~F}$ & 10 & 16 & 0.0929 & $6.97 \mathrm{E}-08$ & 11 & 34 & 0.4943 & $4.42 \mathrm{E}-08$ \\
\hline & $x_{0}^{10}$ & 6 & 6 & 0.1481 & $2.95 \mathrm{E}-07$ & 6 & 6 & 0.0569 & $9.61 \mathrm{E}-09$ & 11 & 34 & 0.5365 & $1.96 \mathrm{E}-07$ \\
\hline & $x_{0}^{1}$ & 7 & 7 & 0.2907 & $1.53 \mathrm{E}-11$ & 7 & 7 & 0.0817 & $1.53 \mathrm{E}-11$ & 8 & 25 & 0.8299 & $7.70 \mathrm{E}-08$ \\
\hline & $x_{0}^{2}$ & 4 & 4 & 0.1811 & $1.97 \mathrm{E}-08$ & 4 & 4 & 0.0448 & $1.97 \mathrm{E}-08$ & 5 & 16 & 0.3797 & $4.73 \mathrm{E}-07$ \\
\hline & $x_{0}^{3}$ & 5 & 5 & 0.1079 & $5.59 \mathrm{E}-09$ & 5 & 5 & 0.0505 & $2.01 \mathrm{E}-09$ & 9 & 28 & 73.4300 & $4.32 \mathrm{E}-07$ \\
\hline \multirow{7}{*}{100000} & $x_{0}^{4}$ & 6 & 6 & 0.1762 & $4.16 \mathrm{E}-07$ & 6 & 6 & 0.0578 & $1.36 \mathrm{E}-08$ & 11 & 34 & 1.1085 & $2.85 \mathrm{E}-07$ \\
\hline & $x_{0}^{5}$ & 6 & 6 & 0.1773 & $4.16 \mathrm{E}-07$ & 6 & 6 & 0.1194 & $1.36 \mathrm{E}-08$ & 11 & 34 & 1.1700 & $2.85 \mathrm{E}-07$ \\
\hline & $x_{0}^{6}$ & 6 & 6 & 0.4746 & $7.86 \mathrm{E}-09$ & 5 & 5 & 0.0935 & $5.65 \mathrm{E}-07$ & 11 & 34 & 1.0038 & $1.68 \mathrm{E}-08$ \\
\hline & $x_{0}^{7}$ & 6 & 6 & 0.5102 & $4.16 \mathrm{E}-07$ & 6 & 6 & 0.1208 & $1.36 \mathrm{E}-08$ & 11 & 34 & 0.7507 & $2.85 \mathrm{E}-07$ \\
\hline & $x_{0}^{8}$ & 6 & 6 & 0.2775 & $4.16 \mathrm{E}-07$ & 6 & 6 & 0.1150 & $1.36 \mathrm{E}-08$ & 11 & 34 & 1.1527 & $2.84 \mathrm{E}-07$ \\
\hline & $x_{0}^{9}$ & $\mathrm{~F}$ & $\mathrm{~F}$ & $\mathrm{~F}$ & $\mathrm{~F}$ & 10 & 16 & 0.2552 & $9.89 \mathrm{E}-08$ & 11 & 34 & 1.4168 & $6.25 \mathrm{E}-08$ \\
\hline & $x_{0}^{10}$ & 6 & 6 & 0.1824 & $4.20 \mathrm{E}-07$ & 6 & 6 & 0.1125 & $1.39 \mathrm{E}-08$ & 11 & 34 & 1.0825 & $2.87 \mathrm{E}-07$ \\
\hline
\end{tabular}


TABle B.3. Numerical results for dfnwt, dfsane and msgp for Problem 3 with given initial points and dimensions.

\begin{tabular}{|c|c|c|c|c|c|c|c|c|c|c|c|c|c|}
\hline \multirow[b]{2}{*}{ Dimension } & \multirow[b]{2}{*}{$x_{0}$} & \multicolumn{4}{|c|}{ dfnwt } & \multicolumn{4}{|c|}{ dfsane } & \multicolumn{4}{|c|}{ msgp } \\
\hline & & \#iter & \#fval & time & Fnorm & \#iter & \#fval & time & Fnorm & \#iter & \#fval & time & Fnorm \\
\hline \multirow{11}{*}{1000} & $x_{0}^{1}$ & 7 & 7 & 0.0082 & $4.51 \mathrm{E}-07$ & 7 & 7 & 0.0056 & $4.51 \mathrm{E}-07$ & 6 & 19 & 0.0112 & $6.51 \mathrm{E}-07$ \\
\hline & $x_{0}^{2}$ & 4 & 4 & 0.0036 & $2.65 \mathrm{E}-09$ & 4 & 4 & 0.0033 & $2.65 \mathrm{E}-09$ & 5 & 16 & 0.0050 & $3.18 \mathrm{E}-07$ \\
\hline & $x_{0}^{3}$ & 5 & 5 & 0.0036 & $6.22 \mathrm{E}-08$ & 5 & 5 & 0.0041 & $4.37 \mathrm{E}-08$ & 8 & 25 & 0.0927 & $1.78 \mathrm{E}-08$ \\
\hline & $x_{0}^{4}$ & 7 & 7 & 0.0105 & $4.87 \mathrm{E}-08$ & 7 & 7 & 0.0027 & $3.44 \mathrm{E}-10$ & 13 & 40 & 0.0126 & $2.00 \mathrm{E}-08$ \\
\hline & $x_{0}^{5}$ & 7 & 7 & 0.0116 & $4.87 \mathrm{E}-08$ & 7 & 7 & 0.0035 & $3.44 \mathrm{E}-10$ & 13 & 40 & 0.0137 & $2.00 \mathrm{E}-08$ \\
\hline & $x_{0}^{6}$ & 7 & 7 & 0.0118 & $1.43 \mathrm{E}-08$ & 7 & 7 & 0.0021 & $4.34 \mathrm{E}-09$ & 9 & 28 & 0.0092 & $2.33 \mathrm{E}-07$ \\
\hline & $x_{0}^{8}$ & 7 & 7 & 0.0057 & $5.07 \mathrm{E}-08$ & 7 & 7 & 0.0019 & $3.57 \mathrm{E}-10$ & 13 & 40 & 0.0100 & $2.14 \mathrm{E}-08$ \\
\hline & $x_{0}^{9}$ & $\mathrm{~F}$ & $\mathrm{~F}$ & $\mathrm{~F}$ & $\mathrm{~F}$ & $\mathrm{~F}$ & $\mathrm{~F}$ & $\mathrm{~F}$ & $\mathrm{~F}$ & 15 & 46 & 0.0137 & $2.26 \mathrm{E}-08$ \\
\hline & $x_{0}^{10}$ & 7 & 7 & 0.0105 & $4.66 \mathrm{E}-08$ & 7 & 7 & 0.0016 & $3.64 \mathrm{E}-10$ & 12 & 37 & 0.0203 & $5.01 \mathrm{E}-08$ \\
\hline & $x_{0}^{1}$ & 8 & 8 & 0.0296 & $9.18 \mathrm{E}-12$ & 8 & 8 & 0.0083 & $9.17 \mathrm{E}-12$ & 7 & 22 & 0.0467 & $1.44 \mathrm{E}-08$ \\
\hline & $x_{0}^{2}$ & 4 & 4 & 0.0164 & $5.92 \mathrm{E}-09$ & 4 & 4 & 0.0041 & $5.92 \mathrm{E}-09$ & 5 & 16 & 0.0186 & $7.10 \mathrm{E}-07$ \\
\hline \multirow{10}{*}{5000} & $x_{0}^{3}$ & 5 & 5 & 0.0166 & $6.22 \mathrm{E}-08$ & 5 & 5 & 0.0141 & 4.37E-08 & 8 & 25 & 1.1229 & $1.78 \mathrm{E}-08$ \\
\hline & $x_{0}^{4}$ & 7 & 7 & 0.0275 & $1.11 \mathrm{E}-07$ & 7 & 7 & 0.0130 & $7.80 \mathrm{E}-10$ & 13 & 40 & 0.0418 & $4.61 \mathrm{E}-08$ \\
\hline & $x_{0}^{5}$ & 7 & 7 & 0.0302 & $1.11 \mathrm{E}-07$ & 7 & 7 & 0.0093 & $7.80 \mathrm{E}-10$ & 13 & 40 & 0.0519 & $4.61 \mathrm{E}-08$ \\
\hline & $x_{0}^{8}$ & 7 & 7 & 0.0320 & $1.12 \mathrm{E}-07$ & 7 & 7 & 0.0069 & $7.86 \mathrm{E}-10$ & 13 & 40 & 0.0652 & $4.67 \mathrm{E}-08$ \\
\hline & $x_{0}^{9}$ & $\mathrm{~F}$ & $\mathrm{~F}$ & $\mathrm{~F}$ & $\mathrm{~F}$ & $\mathrm{~F}$ & $\mathrm{~F}$ & $\mathrm{~F}$ & $\mathrm{~F}$ & 15 & 46 & 0.0786 & $5.05 \mathrm{E}-08$ \\
\hline & $x_{0}^{10}$ & 7 & 7 & 0.0142 & $1.07 \mathrm{E}-07$ & 7 & 7 & 0.0084 & $7.51 \mathrm{E}-10$ & 13 & 40 & 0.0545 & $4.60 \mathrm{E}-08$ \\
\hline & $x_{0}^{1}$ & 8 & 8 & 0.0386 & $1.30 \mathrm{E}-11$ & 8 & 8 & 0.0200 & $1.30 \mathrm{E}-11$ & 7 & 22 & 0.0311 & $2.04 \mathrm{E}-08$ \\
\hline & $x_{0}^{2}$ & 4 & 4 & 0.0225 & $8.38 \mathrm{E}-09$ & 4 & 4 & 0.0075 & $8.38 \mathrm{E}-09$ & 6 & 19 & 0.0614 & $9.95 \mathrm{E}-09$ \\
\hline & $x_{0}^{3}$ & 5 & 5 & 0.0144 & $6.22 \mathrm{E}-08$ & 5 & 5 & 0.0111 & $4.37 \mathrm{E}-08$ & 8 & 25 & 2.3826 & $1.78 \mathrm{E}-08$ \\
\hline & $x_{0}^{4}$ & 7 & 7 & 0.0627 & $1.57 \mathrm{E}-07$ & 7 & 7 & 0.0159 & $1.11 \mathrm{E}-09$ & 13 & 40 & 0.1486 & $6.54 \mathrm{E}-08$ \\
\hline \multirow{6}{*}{10000} & $x_{0}^{5}$ & 7 & 7 & 0.0520 & $1.57 \mathrm{E}-07$ & 7 & 7 & 0.0084 & $1.11 \mathrm{E}-09$ & 13 & 40 & 0.0816 & $6.54 \mathrm{E}-08$ \\
\hline & $x_{0}^{6}$ & 7 & 7 & 0.0199 & $1.43 \mathrm{E}-08$ & 7 & 7 & 0.0119 & 4.33E-09 & 9 & 28 & 0.0475 & $2.40 \mathrm{E}-07$ \\
\hline & $x_{0}^{7}$ & 7 & 7 & 0.0483 & $1.57 \mathrm{E}-07$ & 7 & 7 & 0.0129 & $1.11 \mathrm{E}-09$ & 13 & 40 & 0.0850 & $6.54 \mathrm{E}-08$ \\
\hline & $x_{0}^{8}$ & 7 & 7 & 0.0311 & $1.57 \mathrm{E}-07$ & 7 & 7 & 0.0161 & $1.11 \mathrm{E}-09$ & 13 & 40 & 0.0953 & $6.58 \mathrm{E}-08$ \\
\hline & $x_{0}^{9}$ & $\mathrm{~F}$ & $\mathrm{~F}$ & $\mathrm{~F}$ & $\mathrm{~F}$ & $\mathrm{~F}$ & $\mathrm{~F}$ & $\mathrm{~F}$ & $\mathrm{~F}$ & 15 & 46 & 0.1053 & $7.14 \mathrm{E}-08$ \\
\hline & $x_{0}^{10}$ & 7 & 7 & 0.0425 & $1.54 \mathrm{E}-07$ & 7 & 7 & 0.0149 & $1.04 \mathrm{E}-09$ & 12 & 37 & 0.0663 & $1.07 \mathrm{E}-07$ \\
\hline \multirow{10}{*}{50000} & $x_{0}^{1}$ & 8 & 8 & 0.2026 & $2.90 \mathrm{E}-11$ & 8 & 8 & 0.0429 & $2.90 \mathrm{E}-11$ & 7 & 22 & 0.1691 & $4.56 \mathrm{E}-08$ \\
\hline & $x_{0}^{2}$ & 4 & 4 & 0.0842 & $1.87 \mathrm{E}-08$ & 4 & 4 & 0.0256 & $1.87 \mathrm{E}-08$ & 6 & 19 & 0.1792 & $2.22 \mathrm{E}-08$ \\
\hline & $x_{0}^{3}$ & 5 & 5 & 0.0571 & $6.22 \mathrm{E}-08$ & 5 & 5 & 0.0446 & $4.37 \mathrm{E}-08$ & 8 & 25 & 17.8536 & $1.78 \mathrm{E}-08$ \\
\hline & $x_{0}^{7}$ & 7 & 7 & 0.0905 & $3.51 \mathrm{E}-07$ & 7 & 7 & 0.0420 & $2.48 \mathrm{E}-09$ & 13 & 40 & 0.3265 & $1.47 \mathrm{E}-07$ \\
\hline & $x_{0}^{8}$ & 7 & 7 & 0.0833 & $3.51 \mathrm{E}-07$ & 7 & 7 & 0.0430 & $2.48 \mathrm{E}-09$ & 13 & 40 & 0.2545 & $1.47 \mathrm{E}-07$ \\
\hline & $x_{0}^{9}$ & $\mathrm{~F}$ & $\mathrm{~F}$ & $\mathrm{~F}$ & $\mathrm{~F}$ & $\mathrm{~F}$ & $\mathrm{~F}$ & $\mathrm{~F}$ & $\mathrm{~F}$ & 19 & 58 & 0.4303 & $4.58 \mathrm{E}-08$ \\
\hline & $x_{0}^{10}$ & 7 & 7 & 0.2301 & $3.49 \mathrm{E}-07$ & 7 & 7 & 0.0916 & $2.30 \mathrm{E}-09$ & 13 & 40 & 0.2770 & $1.58 \mathrm{E}-07$ \\
\hline & $x_{0}^{1}$ & 8 & 8 & 0.4108 & $4.10 \mathrm{E}-11$ & 8 & 8 & 0.0719 & $4.10 \mathrm{E}-11$ & 7 & 22 & 0.3374 & $6.45 \mathrm{E}-08$ \\
\hline & $x_{0}^{2}$ & 4 & 4 & 0.2424 & $2.65 \mathrm{E}-08$ & 4 & 4 & 0.0496 & $2.65 \mathrm{E}-08$ & 6 & 19 & 0.2872 & $3.14 \mathrm{E}-08$ \\
\hline & $x_{0}^{3}$ & 5 & 5 & 0.1244 & $6.22 \mathrm{E}-08$ & 5 & 5 & 0.0797 & $4.37 \mathrm{E}-08$ & 8 & 25 & 59.9771 & $1.78 \mathrm{E}-08$ \\
\hline \multirow{7}{*}{100000} & $x_{0}^{4}$ & 7 & 7 & 0.3881 & $4.97 \mathrm{E}-07$ & 7 & 7 & 0.0662 & $3.50 \mathrm{E}-09$ & 13 & 40 & 0.5892 & $2.07 \mathrm{E}-07$ \\
\hline & $x_{0}^{5}$ & 7 & 7 & 0.3485 & $4.97 \mathrm{E}-07$ & 7 & 7 & 0.0794 & $3.50 \mathrm{E}-09$ & 13 & 40 & 0.6391 & $2.07 \mathrm{E}-07$ \\
\hline & $x_{0}^{6}$ & 7 & 7 & 0.1863 & $1.43 \mathrm{E}-08$ & 7 & 7 & 0.0733 & 4.33E-09 & 9 & 28 & 0.4211 & $2.41 \mathrm{E}-07$ \\
\hline & $x_{0}^{7}$ & 7 & 7 & 0.3593 & $4.97 \mathrm{E}-07$ & 7 & 7 & 0.0822 & $3.50 \mathrm{E}-09$ & 13 & 40 & 0.7034 & $2.07 \mathrm{E}-07$ \\
\hline & $x_{0}^{8}$ & 7 & 7 & 0.4207 & $4.97 \mathrm{E}-07$ & 7 & 7 & 0.0636 & $3.50 \mathrm{E}-09$ & 13 & 40 & 0.4962 & $2.07 \mathrm{E}-07$ \\
\hline & $x_{0}^{9}$ & $\mathrm{~F}$ & $\mathrm{~F}$ & $\mathrm{~F}$ & $\mathrm{~F}$ & $\mathrm{~F}$ & $\mathrm{~F}$ & $\mathrm{~F}$ & $\mathrm{~F}$ & 19 & 58 & 1.1126 & $6.48 \mathrm{E}-08$ \\
\hline & $x_{0}^{10}$ & 7 & 7 & 0.2652 & $4.98 \mathrm{E}-07$ & 7 & 7 & 0.0650 & $3.46 \mathrm{E}-09$ & 13 & 40 & 0.5084 & $1.99 \mathrm{E}-07$ \\
\hline
\end{tabular}


TABle B.4. Numerical results for dfnwt, dfsane and msgp for Problem 4 with given initial points and dimensions.

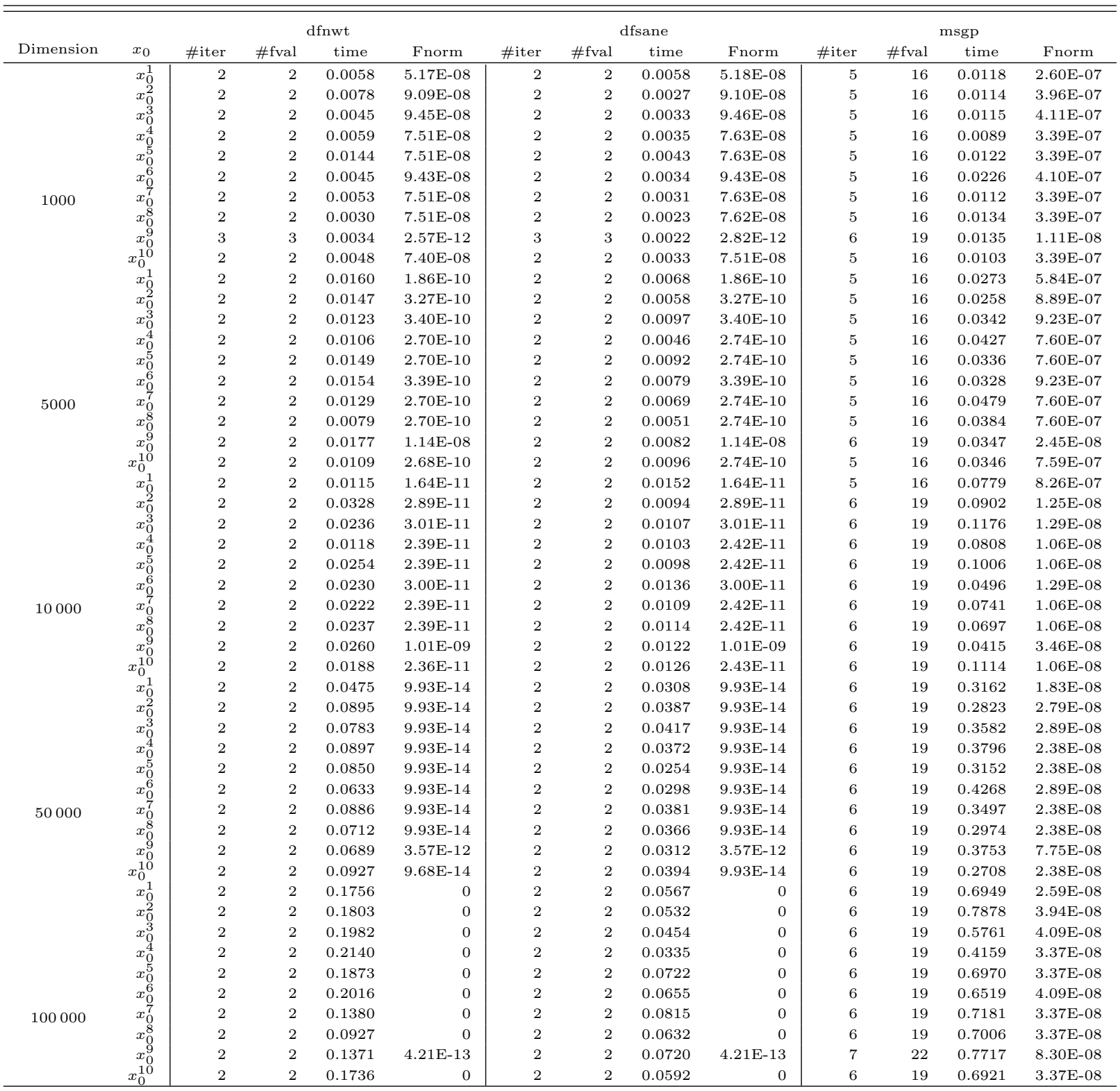


TABle B.5. Numerical results for dfnwt, dfsane and msgp for Problem 5 with given initial points and dimensions.

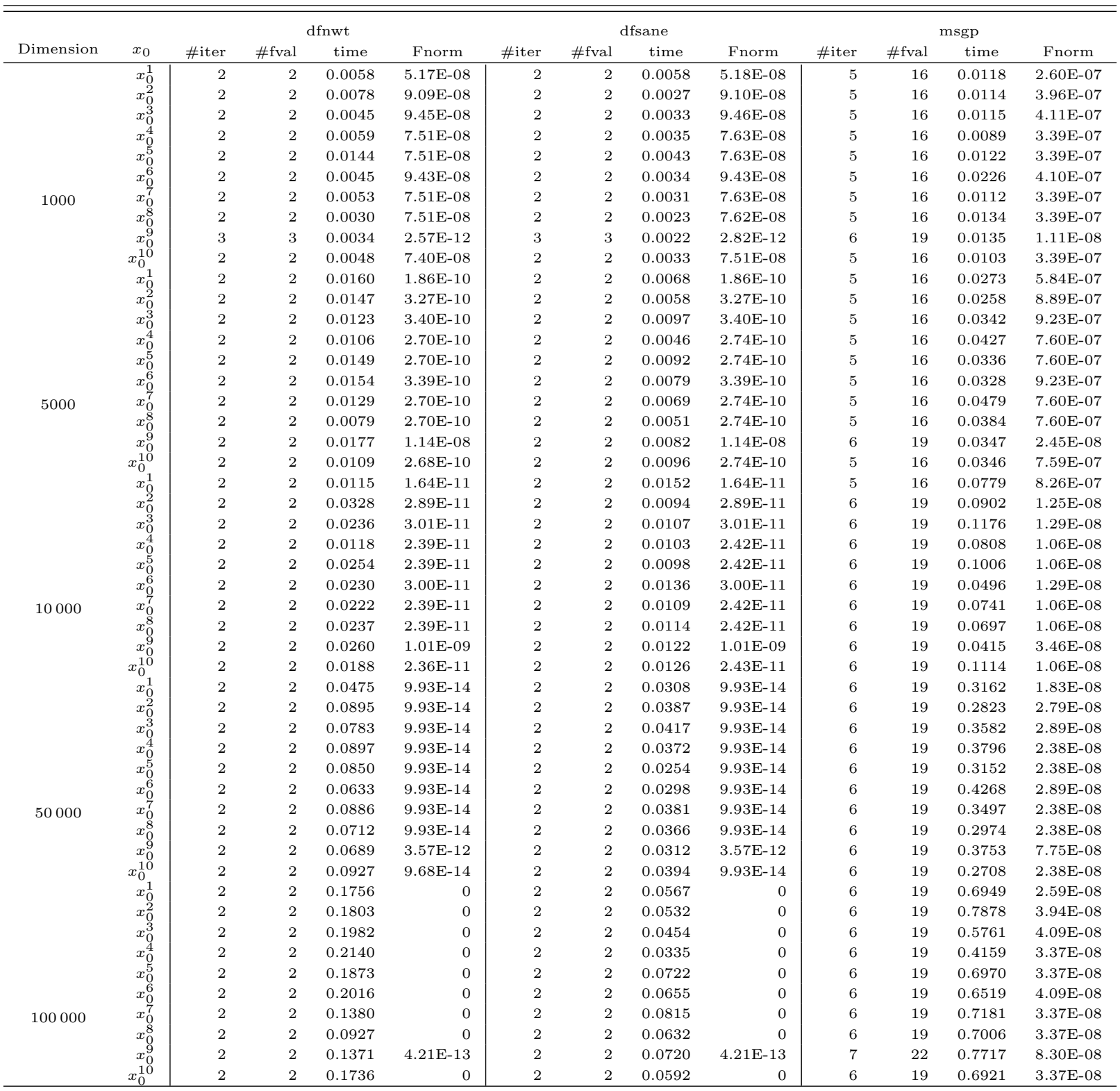


TABle B.6. Numerical results for dfnwt, dfsane and msgp for Problem 6 with given initial points and dimensions.

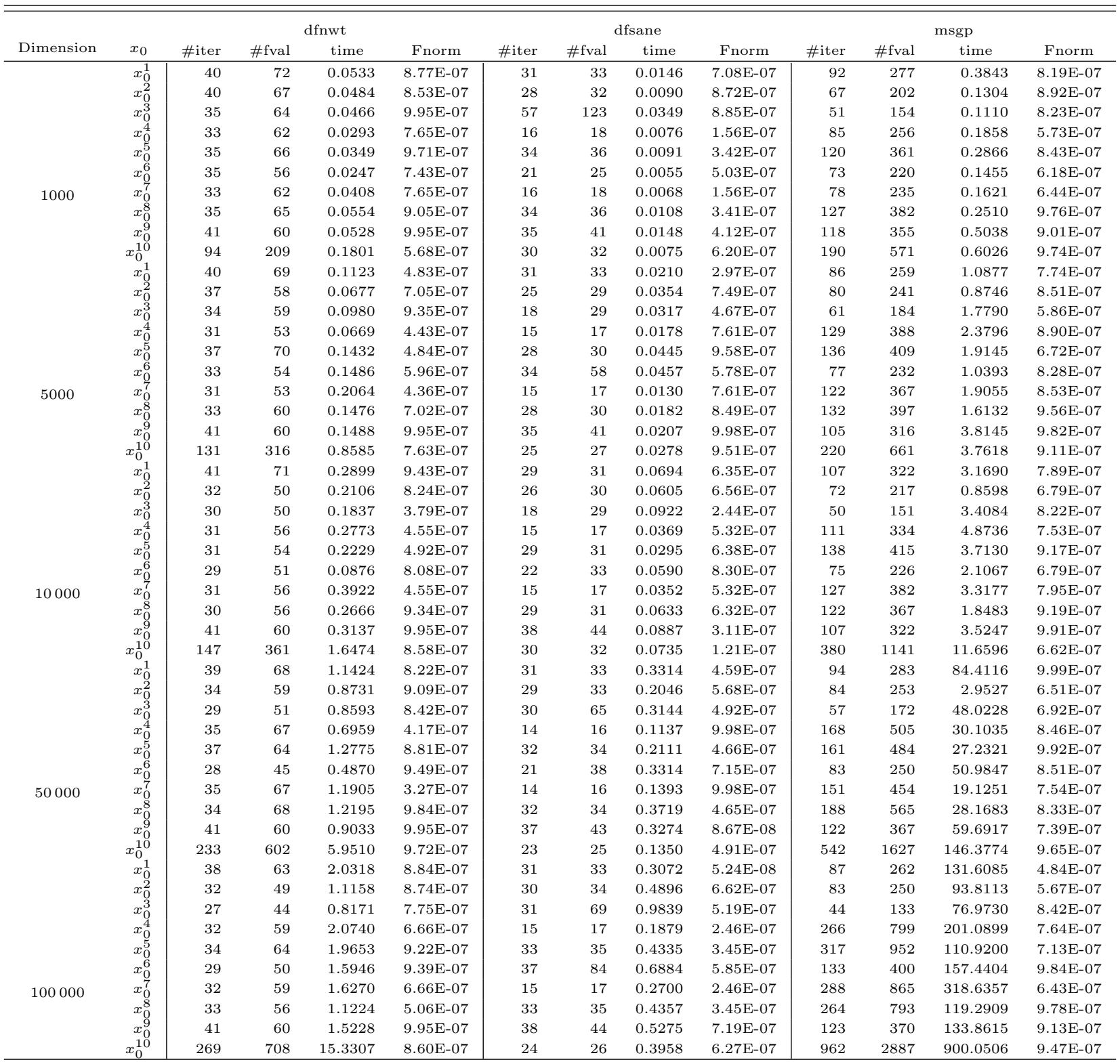


TABle B.7. Numerical results for dfnwt, dfsane and msgp for Problem 7 with given initial points and dimensions.




TABle B.8. Numerical results for dfnwt, dfsane and msgp for Problem 8 with given initial points and dimensions.

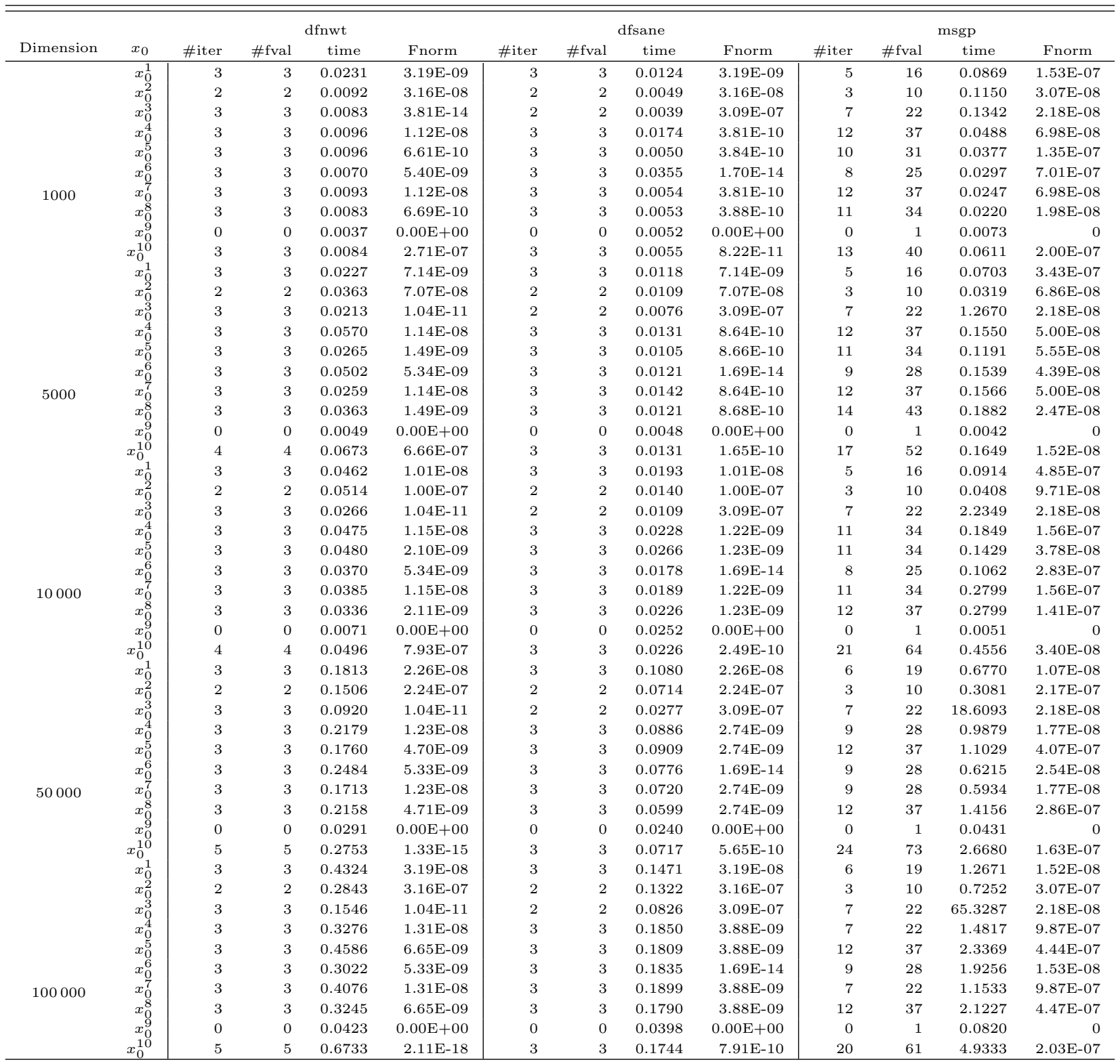


TABle B.9. Numerical results for dfnwt, dfsane and msgp for Problem 9 with given initial points and dimensions.

\begin{tabular}{|c|c|c|c|c|c|c|c|c|c|c|c|c|c|}
\hline \multirow[b]{2}{*}{ Dimension } & \multirow[b]{2}{*}{$x_{0}$} & \multicolumn{4}{|c|}{ dfnwt } & \multicolumn{4}{|c|}{ dfsane } & \multicolumn{4}{|c|}{ msgp } \\
\hline & & \#iter & \#fval & time & Fnorm & \#iter & \#fval & time & Fnorm & \#iter & \#fval & time & Fnorm \\
\hline \multirow{11}{*}{1000} & $x_{0}^{1}$ & $\mathrm{~F}$ & $\mathrm{~F}$ & $\mathrm{~F}$ & $\mathrm{~F}$ & 9 & 19 & 0.0711 & $7.69 \mathrm{E}-08$ & 50 & 151 & 0.5026 & $9.73 \mathrm{E}-07$ \\
\hline & $x_{0}^{2}$ & $\mathrm{~F}$ & $\mathrm{~F}$ & $\mathrm{~F}$ & $\mathrm{~F}$ & 21 & 30 & 0.0436 & $3.77 \mathrm{E}-07$ & 67 & 202 & 0.4269 & $9.80 \mathrm{E}-07$ \\
\hline & $x_{0}^{3}$ & 6 & 10 & 0.1611 & $3.92 \mathrm{E}-11$ & 27 & 41 & 0.0285 & $1.31 \mathrm{E}-07$ & 32 & 97 & 0.3032 & $5.63 \mathrm{E}-07$ \\
\hline & $x_{0}^{4}$ & 6 & 10 & 0.0222 & $1.14 \mathrm{E}-07$ & 8 & 16 & 0.0115 & $5.39 \mathrm{E}-07$ & 35 & 106 & 0.1123 & $7.46 \mathrm{E}-07$ \\
\hline & $x_{0}^{5}$ & 7 & 11 & 0.0375 & $4.57 \mathrm{E}-12$ & 8 & 16 & 0.0230 & $4.30 \mathrm{E}-07$ & 31 & 94 & 0.0933 & $5.80 \mathrm{E}-07$ \\
\hline & $x_{0}^{6}$ & 6 & 10 & 0.0293 & $9.34 \mathrm{E}-10$ & 12 & 22 & 0.0118 & $4.28 \mathrm{E}-08$ & 48 & 145 & 0.3150 & $8.87 \mathrm{E}-07$ \\
\hline & $x_{0}^{7}$ & 6 & 10 & 0.0291 & $1.14 \mathrm{E}-07$ & 8 & 16 & 0.0138 & $5.39 \mathrm{E}-07$ & 37 & 112 & 0.1361 & $7.37 \mathrm{E}-07$ \\
\hline & $x_{0}^{8}$ & 7 & 11 & 0.0135 & $4.70 \mathrm{E}-12$ & 8 & 16 & 0.0138 & $4.22 \mathrm{E}-07$ & 33 & 100 & 0.0804 & $7.52 \mathrm{E}-07$ \\
\hline & $x_{0}^{9}$ & $\mathrm{~F}$ & $\mathrm{~F}$ & $\mathrm{~F}$ & $\mathrm{~F}$ & 20 & 29 & 0.0235 & $7.35 \mathrm{E}-07$ & 46 & 139 & 0.2161 & $7.70 \mathrm{E}-07$ \\
\hline & $x_{0}^{10}$ & 7 & 11 & 0.0390 & $3.08 \mathrm{E}-12$ & 9 & 17 & 0.0116 & $6.06 \mathrm{E}-08$ & 38 & 115 & 0.0732 & $7.30 \mathrm{E}-07$ \\
\hline & $x_{0}^{1}$ & $\mathrm{~F}$ & $\mathrm{~F}$ & $\mathrm{~F}$ & $\mathrm{~F}$ & 10 & 22 & 0.0625 & $7.30 \mathrm{E}-08$ & 60 & 181 & 1.1448 & $6.36 \mathrm{E}-07$ \\
\hline \multirow{12}{*}{5000} & $x_{0}^{2}$ & $\mathrm{~F}$ & $\mathrm{~F}$ & $\mathrm{~F}$ & $\mathrm{~F}$ & 9 & 19 & 0.0457 & $9.03 \mathrm{E}-07$ & 73 & 220 & 1.4328 & $5.90 \mathrm{E}-07$ \\
\hline & $x_{0}^{3}$ & $\mathrm{~F}$ & $\mathrm{~F}$ & $\mathrm{~F}$ & $\mathrm{~F}$ & 27 & 37 & 0.0764 & $9.75 \mathrm{E}-07$ & 79 & 238 & 1.1495 & $8.51 \mathrm{E}-07$ \\
\hline & $x_{0}^{4}$ & 6 & 10 & 0.0250 & $7.43 \mathrm{E}-08$ & 9 & 19 & 0.0694 & $2.80 \mathrm{E}-07$ & 65 & 196 & 1.7019 & $8.20 \mathrm{E}-07$ \\
\hline & $x_{0}^{5}$ & 6 & 10 & 0.0506 & $4.53 \mathrm{E}-11$ & 10 & 20 & 0.0729 & $2.75 \mathrm{E}-08$ & 51 & 154 & 1.0233 & $8.90 \mathrm{E}-07$ \\
\hline & $x_{0}^{6}$ & $\mathrm{~F}$ & $\mathrm{~F}$ & F & $\mathrm{F}$ & 24 & 39 & 0.0990 & $1.22 \mathrm{E}-07$ & 112 & 337 & 1.1675 & $8.92 \mathrm{E}-07$ \\
\hline & $x_{0}^{7}$ & 6 & 10 & 0.0195 & $7.43 \mathrm{E}-08$ & 9 & 19 & 0.0353 & $2.80 \mathrm{E}-07$ & 59 & 178 & 0.3586 & $7.84 \mathrm{E}-07$ \\
\hline & $x_{0}^{8}$ & 6 & 10 & 0.0593 & $1.08 \mathrm{E}-10$ & 9 & 19 & 0.0447 & $9.85 \mathrm{E}-07$ & 43 & 130 & 0.4362 & $7.49 \mathrm{E}-07$ \\
\hline & $x_{0}^{9}$ & $\mathrm{~F}$ & $\mathrm{~F}$ & F & $\mathrm{F}$ & 23 & 34 & 0.0804 & $1.46 \mathrm{E}-07$ & 63 & 190 & 2.0268 & $7.53 \mathrm{E}-07$ \\
\hline & $x_{0}^{10}$ & 6 & 10 & 0.0904 & $3.06 \mathrm{E}-09$ & 10 & 20 & 0.0817 & $1.35 \mathrm{E}-08$ & 50 & 151 & 1.0678 & $6.00 \mathrm{E}-07$ \\
\hline & $x_{0}^{1}$ & 37 & 88 & 0.8243 & $6.05 \mathrm{E}-07$ & 10 & 22 & 0.0858 & $1.15 \mathrm{E}-08$ & 60 & 181 & 1.1993 & $9.89 \mathrm{E}-07$ \\
\hline & $x_{0}^{2}$ & 7 & 11 & 0.1119 & $1.27 \mathrm{E}-10$ & 10 & 20 & 0.0582 & $9.55 \mathrm{E}-09$ & 102 & 307 & 4.8826 & $9.01 \mathrm{E}-07$ \\
\hline & $x_{0}^{3}$ & $\mathrm{~F}$ & $\mathrm{~F}$ & $\mathrm{~F}$ & $\mathrm{~F}$ & 23 & 33 & 0.1650 & $1.17 \mathrm{E}-07$ & 113 & 340 & 3.3422 & $5.45 \mathrm{E}-07$ \\
\hline \multirow{7}{*}{10000} & $x_{0}^{4}$ & 5 & 9 & 0.1246 & $9.26 \mathrm{E}-07$ & 10 & 20 & 0.0896 & $1.09 \mathrm{E}-08$ & 73 & 220 & 3.1656 & $6.60 \mathrm{E}-07$ \\
\hline & $x_{0}^{5}$ & 7 & 11 & 0.1311 & $1.77 \mathrm{E}-09$ & 9 & 19 & 0.0787 & $3.11 \mathrm{E}-07$ & 69 & 208 & 3.2133 & $7.06 \mathrm{E}-07$ \\
\hline & $x_{0}^{6}$ & 7 & 12 & 0.0808 & $1.37 \mathrm{E}-10$ & 88 & 107 & 0.4210 & $6.62 \mathrm{E}-07$ & 107 & 322 & 3.6785 & $8.99 \mathrm{E}-07$ \\
\hline & $x_{0}^{7}$ & 5 & 9 & 0.0664 & $9.26 \mathrm{E}-07$ & 10 & 20 & 0.0770 & $1.09 \mathrm{E}-08$ & 58 & 175 & 2.1563 & $6.59 \mathrm{E}-07$ \\
\hline & $x_{0}^{8}$ & 7 & 11 & 0.1071 & $1.75 \mathrm{E}-09$ & 9 & 19 & 0.1426 & $3.15 \mathrm{E}-07$ & 54 & 163 & 1.8405 & $9.31 \mathrm{E}-07$ \\
\hline & $x_{0}^{9}$ & $\mathrm{~F}$ & $\mathrm{~F}$ & $\mathrm{~F}$ & $\mathrm{~F}$ & 24 & 35 & 0.3383 & $5.25 \mathrm{E}-07$ & 98 & 295 & 4.9775 & $6.22 \mathrm{E}-07$ \\
\hline & $x_{0}^{10}$ & 7 & 11 & 0.0529 & $6.64 \mathrm{E}-11$ & 10 & 20 & 0.0679 & $2.14 \mathrm{E}-07$ & 56 & 169 & 1.1605 & $9.42 \mathrm{E}-07$ \\
\hline \multirow{13}{*}{50000} & $x_{0}^{1}$ & $\mathrm{~F}$ & $\mathrm{~F}$ & F & $\mathrm{F}$ & 11 & 25 & 0.3264 & $6.24 \mathrm{E}-08$ & 62 & 187 & 10.0833 & $7.58 \mathrm{E}-07$ \\
\hline & $x_{0}^{2}$ & 7 & 12 & 0.1846 & $1.46 \mathrm{E}-09$ & 12 & 26 & 0.8253 & $6.72 \mathrm{E}-07$ & 51 & 154 & 9.2918 & $7.31 \mathrm{E}-07$ \\
\hline & $x_{0}^{3}$ & 7 & 12 & 0.3246 & $6.38 \mathrm{E}-08$ & $\mathrm{~F}$ & $\mathrm{~F}$ & $\mathrm{~F}$ & $\mathrm{~F}$ & 53 & 160 & 9.7014 & $8.61 \mathrm{E}-07$ \\
\hline & $x_{0}^{4}$ & 7 & 12 & 0.4709 & $9.22 \mathrm{E}-10$ & 10 & 22 & 0.1655 & $6.93 \mathrm{E}-07$ & 56 & 169 & 6.7278 & $5.70 \mathrm{E}-07$ \\
\hline & $x_{0}^{5}$ & 7 & 12 & 0.3799 & $1.37 \mathrm{E}-08$ & 10 & 22 & 0.2751 & $8.16 \mathrm{E}-07$ & $\mathrm{~F}$ & $\mathrm{~F}$ & $\mathrm{~F}$ & $\mathrm{~F}$ \\
\hline & $x_{0}^{6}$ & $\mathrm{~F}$ & $\mathrm{~F}$ & $\mathrm{~F}$ & $\mathrm{~F}$ & 31 & 44 & 1.2958 & $4.08 \mathrm{E}-07$ & $\mathrm{~F}$ & $\mathrm{~F}$ & $\mathrm{~F}$ & $\mathrm{~F}$ \\
\hline & $x_{0}^{7}$ & 7 & 12 & 0.1788 & $9.22 \mathrm{E}-10$ & 10 & 22 & 0.3327 & $6.93 \mathrm{E}-07$ & 87 & 262 & 7.5469 & $7.97 \mathrm{E}-07$ \\
\hline & $x_{0}^{8}$ & 7 & 12 & 0.4917 & $1.38 \mathrm{E}-08$ & 10 & 22 & 0.6035 & $8.08 \mathrm{E}-07$ & 58 & 175 & 12.0776 & $8.32 \mathrm{E}-07$ \\
\hline & $x_{0}^{9}$ & $\mathrm{~F}$ & $\mathrm{~F}$ & $\mathrm{~F}$ & $\mathrm{~F}$ & 25 & 38 & 0.9191 & $8.68 \mathrm{E}-07$ & 515 & 1546 & 201.1150 & $5.91 \mathrm{E}-07$ \\
\hline & $x_{0}^{10}$ & 7 & 12 & 0.4765 & $3.41 \mathrm{E}-09$ & 10 & 22 & 0.2823 & $4.48 \mathrm{E}-07$ & 60 & 181 & 9.4425 & $5.33 \mathrm{E}-07$ \\
\hline & $x_{0}^{1}$ & $\mathrm{~F}$ & $\mathrm{~F}$ & $\mathrm{~F}$ & $\mathrm{~F}$ & 10 & 24 & 1.1012 & $3.35 \mathrm{E}-07$ & 59 & 178 & 29.5893 & $5.30 \mathrm{E}-07$ \\
\hline & $x_{0}^{2}$ & 7 & 12 & 0.3711 & $4.11 \mathrm{E}-09$ & 10 & 22 & 0.8940 & $3.07 \mathrm{E}-07$ & 57 & 172 & 22.1624 & $8.46 \mathrm{E}-07$ \\
\hline & $x_{0}^{3}$ & $\mathrm{~F}$ & $\mathrm{~F}$ & $\mathrm{~F}$ & $\mathrm{~F}$ & $\mathrm{~F}$ & $\mathrm{~F}$ & $\mathrm{~F}$ & $\mathrm{~F}$ & 49 & 148 & 23.8793 & $5.04 \mathrm{E}-07$ \\
\hline \multirow{7}{*}{100000} & $x_{0}^{4}$ & 7 & 12 & 0.9437 & $2.61 \mathrm{E}-09$ & 10 & 22 & 0.4221 & $3.38 \mathrm{E}-07$ & 58 & 175 & 25.5587 & $7.92 \mathrm{E}-07$ \\
\hline & $x_{0}^{5}$ & 7 & 12 & 1.0413 & $2.45 \mathrm{E}-08$ & 10 & 22 & 0.3702 & $9.44 \mathrm{E}-07$ & 52 & 157 & 21.8180 & $5.14 \mathrm{E}-07$ \\
\hline & $x_{0}^{6}$ & $\mathrm{~F}$ & $\mathrm{~F}$ & $\mathrm{~F}$ & $\mathrm{~F}$ & 17 & 31 & 0.6667 & $9.47 \mathrm{E}-07$ & 50 & 151 & 23.8697 & $5.05 \mathrm{E}-07$ \\
\hline & $x_{0}^{7}$ & 7 & 12 & 0.4419 & $2.61 \mathrm{E}-09$ & 10 & 22 & 0.3764 & $3.38 \mathrm{E}-07$ & 58 & 175 & 22.9366 & $7.86 \mathrm{E}-07$ \\
\hline & $x_{0}^{8}$ & 7 & 12 & 0.9948 & $2.45 \mathrm{E}-08$ & 10 & 22 & 1.0433 & $9.54 \mathrm{E}-07$ & 52 & 157 & 22.3546 & $5.16 \mathrm{E}-07$ \\
\hline & $x_{0}^{9}$ & $\mathrm{~F}$ & $\mathrm{~F}$ & $\mathrm{~F}$ & $\mathrm{~F}$ & 26 & 39 & 1.1405 & $4.99 \mathrm{E}-07$ & 1001 & 3004 & 1333.5561 & 98731745 \\
\hline & $x_{0}^{10}$ & 7 & 12 & 0.9773 & 7.27E-09 & 11 & 23 & 0.8366 & $2.26 \mathrm{E}-08$ & 59 & 178 & 20.6743 & $9.16 \mathrm{E}-07$ \\
\hline
\end{tabular}


TABle B.10. Numerical results for dfnwt, dfsane and msgp for Problem 10 with given initial points and dimensions.

\begin{tabular}{|c|c|c|c|c|c|c|c|c|c|c|c|c|c|}
\hline \multirow[b]{2}{*}{ Dimension } & \multirow[b]{2}{*}{$x_{0}$} & \multicolumn{4}{|c|}{ dfnwt } & \multicolumn{4}{|c|}{ dfsane } & \multicolumn{4}{|c|}{ msgp } \\
\hline & & \#iter & \#fval & time & Fnorm & \#iter & \#fval & time & Fnorm & \#iter & \#fval & time & Fnorm \\
\hline \multirow{16}{*}{1000} & $x_{0}^{1}$ & 141 & 222 & 0.2429 & $6.95 \mathrm{E}-07$ & $\mathrm{~F}$ & $\mathrm{~F}$ & $\mathrm{~F}$ & $\mathrm{~F}$ & 81 & 244 & 0.3434 & $9.92 \mathrm{E}-07$ \\
\hline & $x_{0}^{2}$ & 133 & 209 & 0.1519 & $9.33 \mathrm{E}-07$ & $\mathrm{~F}$ & $\mathrm{~F}$ & $\mathrm{~F}$ & F & 79 & 238 & 0.2446 & $9.83 \mathrm{E}-07$ \\
\hline & $x_{0}^{3}$ & 159 & 261 & 0.1427 & $9.99 \mathrm{E}-07$ & F & $\mathrm{F}$ & $\mathrm{F}$ & F & 47 & 142 & 0.2845 & $9.72 \mathrm{E}-07$ \\
\hline & $x_{0}^{4}$ & 107 & 174 & 0.1232 & $8.65 \mathrm{E}-07$ & $\mathrm{~F}$ & $\mathrm{~F}$ & $\mathrm{~F}$ & $\mathrm{~F}$ & 113 & 340 & 0.2719 & $9.60 \mathrm{E}-07$ \\
\hline & $x_{0}^{5}$ & 87 & 143 & 0.1853 & $6.61 \mathrm{E}-07$ & $\mathrm{~F}$ & $\mathrm{~F}$ & $\mathrm{~F}$ & $\mathrm{~F}$ & 77 & 232 & 0.1107 & $6.66 \mathrm{E}-07$ \\
\hline & $x_{0}^{6}$ & 146 & 216 & 0.2215 & $9.74 \mathrm{E}-07$ & F & $\mathrm{F}$ & $\mathrm{F}$ & F & 79 & 238 & 0.1403 & $9.26 \mathrm{E}-07$ \\
\hline & $x_{0}^{7}$ & 111 & 191 & 0.2251 & $7.69 \mathrm{E}-07$ & $\mathrm{~F}$ & $\mathrm{~F}$ & $\mathrm{~F}$ & $\mathrm{~F}$ & 92 & 277 & 0.2784 & $8.53 \mathrm{E}-07$ \\
\hline & $x_{0}^{8}$ & 118 & 185 & 0.2335 & $9.00 \mathrm{E}-07$ & $\mathrm{~F}$ & $\mathrm{~F}$ & $\mathrm{~F}$ & $\mathrm{~F}$ & 90 & 271 & 0.2394 & $9.00 \mathrm{E}-07$ \\
\hline & $x_{0}^{9}$ & $\mathrm{~F}$ & $\mathrm{~F}$ & $\mathrm{~F}$ & $\mathrm{~F}$ & $\mathrm{~F}$ & $\mathrm{~F}$ & $\mathrm{~F}$ & $\mathrm{~F}$ & $\mathrm{~F}$ & $\mathrm{~F}$ & $\mathrm{~F}$ & $\mathrm{~F}$ \\
\hline & $x_{0}^{10}$ & 249 & 500 & 0.1952 & $8.82 \mathrm{E}-07$ & $\mathrm{~F}$ & $\mathrm{~F}$ & $\mathrm{~F}$ & $\mathrm{~F}$ & 883 & 2650 & 4.4959 & $9.96 \mathrm{E}-07$ \\
\hline & $x_{0}^{1}$ & 121 & 195 & 0.4829 & $9.72 \mathrm{E}-07$ & F & $\mathrm{F}$ & $\mathrm{F}$ & F & $\mathrm{F}$ & $\mathrm{F}$ & $\mathrm{F}$ & $\mathrm{F}$ \\
\hline & $x_{0}^{2}$ & 156 & 250 & 0.5675 & $9.87 \mathrm{E}-07$ & F & $\mathrm{F}$ & $\mathrm{F}$ & F & 81 & 244 & 0.6790 & $8.94 \mathrm{E}-07$ \\
\hline & $x_{0}^{3}$ & 161 & 261 & 0.6929 & $7.20 \mathrm{E}-07$ & $\mathrm{~F}$ & $\mathrm{~F}$ & $\mathrm{~F}$ & $\mathrm{~F}$ & 67 & 202 & 7.1707 & $9.81 \mathrm{E}-07$ \\
\hline & $x_{0}^{4}$ & 113 & 187 & 0.5143 & $9.20 \mathrm{E}-07$ & $\mathrm{~F}$ & $\mathrm{~F}$ & $\mathrm{~F}$ & $\mathrm{~F}$ & $\mathrm{~F}$ & $\mathrm{~F}$ & $\mathrm{~F}$ & $\mathrm{~F}$ \\
\hline & $x_{0}^{5}$ & 143 & 227 & 0.9067 & $9.37 \mathrm{E}-07$ & $\mathrm{~F}$ & $\mathrm{~F}$ & $\mathrm{~F}$ & $\mathrm{~F}$ & $\mathrm{~F}$ & $\mathrm{~F}$ & $\mathrm{~F}$ & $\mathrm{~F}$ \\
\hline & $x_{0}^{6}$ & 138 & 221 & 0.5314 & $9.33 \mathrm{E}-07$ & F & $\mathrm{F}$ & $\mathrm{F}$ & $\mathrm{F}$ & 81 & 244 & 0.8107 & $1.00 \mathrm{E}-06$ \\
\hline \multirow[t]{10}{*}{5000} & $x_{0}^{7}$ & 101 & 172 & 0.3722 & $7.60 \mathrm{E}-07$ & $\mathrm{~F}$ & $\mathrm{~F}$ & $\mathrm{~F}$ & $\mathrm{~F}$ & $\mathrm{~F}$ & $\mathrm{~F}$ & $\mathrm{~F}$ & $\mathrm{~F}$ \\
\hline & $x_{0}^{8}$ & 109 & 176 & 0.3498 & $8.90 \mathrm{E}-07$ & $\mathrm{~F}$ & $\mathrm{~F}$ & $\mathrm{~F}$ & $\mathrm{~F}$ & $\mathrm{~F}$ & $\mathrm{~F}$ & $\mathrm{~F}$ & $\mathrm{~F}$ \\
\hline & $x_{0}^{9}$ & 990 & 9850 & 23.4897 & $9.91 \mathrm{E}-07$ & F & $\mathrm{F}$ & $\mathrm{F}$ & $\mathrm{F}$ & $\mathrm{F}$ & $\mathrm{F}$ & $\mathrm{F}$ & $\mathrm{F}$ \\
\hline & $x_{0}^{10}$ & 460 & 951 & 2.6919 & $8.48 \mathrm{E}-07$ & F & $\mathrm{F}$ & $\mathrm{F}$ & F & $\mathrm{F}$ & $\mathrm{F}$ & $\mathrm{F}$ & $\mathrm{F}$ \\
\hline & $x_{0}^{1}$ & 138 & 222 & 0.5810 & $9.38 \mathrm{E}-07$ & F & $\mathrm{F}$ & $\mathrm{F}$ & F & $\mathrm{F}$ & $\mathrm{F}$ & $\mathrm{F}$ & $\mathrm{F}$ \\
\hline & $x_{0}^{2}$ & 127 & 214 & 0.9605 & $7.21 \mathrm{E}-07$ & F & $\mathrm{F}$ & $\mathrm{F}$ & $\mathrm{F}$ & 86 & 259 & 1.6437 & $6.98 \mathrm{E}-07$ \\
\hline & $x_{0}^{3}$ & 99 & 167 & 0.6457 & $9.66 \mathrm{E}-07$ & $\mathrm{~F}$ & $\mathrm{~F}$ & $\mathrm{~F}$ & $\mathrm{~F}$ & 65 & 196 & 15.7560 & $9.66 \mathrm{E}-07$ \\
\hline & $x_{0}^{4}$ & 135 & 214 & 1.6665 & $6.63 \mathrm{E}-07$ & F & $\mathrm{F}$ & $\mathrm{F}$ & F & $\mathrm{F}$ & $\mathrm{F}$ & $\mathrm{F}$ & $\mathrm{F}$ \\
\hline & $x_{0}^{5}$ & 126 & 200 & 1.5207 & $9.93 \mathrm{E}-07$ & F & $\mathrm{F}$ & $\mathrm{F}$ & $\mathrm{F}$ & $\mathrm{F}$ & $\mathrm{F}$ & $\mathrm{F}$ & $\mathrm{F}$ \\
\hline & $x_{0}^{6}$ & 153 & 249 & 1.1652 & $9.36 \mathrm{E}-07$ & F & $\mathrm{F}$ & $\mathrm{F}$ & F & 87 & 262 & 2.6951 & $9.99 \mathrm{E}-07$ \\
\hline \multirow{10}{*}{10000} & $x_{0}^{7}$ & 172 & 278 & 1.9711 & $8.48 \mathrm{E}-07$ & $\mathrm{~F}$ & $\mathrm{~F}$ & $\mathrm{~F}$ & $\mathrm{~F}$ & $\mathrm{~F}$ & $\mathrm{~F}$ & $\mathrm{~F}$ & $\mathrm{~F}$ \\
\hline & $x_{0}^{8}$ & 132 & 211 & 1.2663 & $8.70 \mathrm{E}-07$ & $\mathrm{~F}$ & $\mathrm{~F}$ & $\mathrm{~F}$ & F & $\mathrm{F}$ & $\mathrm{F}$ & $\mathrm{F}$ & $\mathrm{F}$ \\
\hline & $x_{0}^{9}$ & 961 & 9498 & 23.2381 & $8.65 \mathrm{E}-07$ & F & $\mathrm{F}$ & $\mathrm{F}$ & F & $\mathrm{F}$ & $\mathrm{F}$ & $\mathrm{F}$ & $\mathrm{F}$ \\
\hline & $x_{0}^{10}$ & 670 & 1534 & 5.9113 & $7.96 \mathrm{E}-07$ & $\mathrm{~F}$ & $\mathrm{~F}$ & $\mathrm{~F}$ & F & $\mathrm{F}$ & $\mathrm{F}$ & $\mathrm{F}$ & $\mathrm{F}$ \\
\hline & $x_{0}^{1}$ & 124 & 198 & 3.1203 & $9.92 \mathrm{E}-07$ & $\mathrm{~F}$ & $\mathrm{~F}$ & $\mathrm{~F}$ & F & $\mathrm{F}$ & $\mathrm{F}$ & $\mathrm{F}$ & $\mathrm{F}$ \\
\hline & $x_{0}^{2}$ & 119 & 194 & 2.6387 & $6.32 \mathrm{E}-07$ & F & $\mathrm{F}$ & $\mathrm{F}$ & $\mathrm{F}$ & 198 & 595 & 8.5793 & $9.11 \mathrm{E}-07$ \\
\hline & $x_{0}^{3}$ & 104 & 173 & 2.0316 & $9.36 \mathrm{E}-07$ & $\mathrm{~F}$ & $\mathrm{~F}$ & $\mathrm{~F}$ & $\mathrm{~F}$ & 58 & 175 & 126.7026 & $8.39 \mathrm{E}-07$ \\
\hline & $x_{0}^{4}$ & 127 & 205 & 3.0142 & $6.67 \mathrm{E}-07$ & $\mathrm{~F}$ & $\mathrm{~F}$ & $\mathrm{~F}$ & F & $\mathrm{F}$ & $\mathrm{F}$ & $\mathrm{F}$ & $\mathrm{F}$ \\
\hline & $x_{0}^{5}$ & 129 & 193 & 4.3183 & $9.49 \mathrm{E}-07$ & F & $\mathrm{F}$ & $\mathrm{F}$ & F & $\mathrm{F}$ & F & $\mathrm{F}$ & $\mathrm{F}$ \\
\hline & $x_{0}^{6}$ & 139 & 233 & 6.2279 & $8.72 \mathrm{E}-07$ & $\mathrm{~F}$ & $\mathrm{~F}$ & $\mathrm{~F}$ & F & 70 & 211 & 4.1423 & $9.76 \mathrm{E}-07$ \\
\hline \multirow[t]{10}{*}{50000} & $x_{0}^{7}$ & 94 & 143 & 3.5436 & $7.93 \mathrm{E}-07$ & F & $\mathrm{F}$ & $\mathrm{F}$ & $\mathrm{F}$ & $\mathrm{F}$ & $\mathrm{F}$ & $\mathrm{F}$ & $\mathrm{F}$ \\
\hline & $x_{0}^{8}$ & 125 & 188 & 4.0646 & $8.06 \mathrm{E}-07$ & F & $\mathrm{F}$ & $\mathrm{F}$ & $\mathrm{F}$ & $\mathrm{F}$ & $\mathrm{F}$ & $\mathrm{F}$ & $\mathrm{F}$ \\
\hline & $x_{0}^{9}$ & 245 & 1090 & 12.9963 & $8.50 \mathrm{E}-07$ & F & $\mathrm{F}$ & $\mathrm{F}$ & F & $\mathrm{F}$ & $\mathrm{F}$ & $\mathrm{F}$ & $\mathrm{F}$ \\
\hline & $x_{0}^{10}$ & $\mathrm{~F}$ & $\mathrm{~F}$ & $\mathrm{~F}$ & $\mathrm{~F}$ & $\mathrm{~F}$ & $\mathrm{~F}$ & $\mathrm{~F}$ & $\mathrm{~F}$ & $\mathrm{~F}$ & $\mathrm{~F}$ & $\mathrm{~F}$ & $\mathrm{~F}$ \\
\hline & $x_{0}^{1}$ & 150 & 244 & 5.8961 & $8.89 \mathrm{E}-07$ & F & $\mathrm{F}$ & $\mathrm{F}$ & $\mathrm{F}$ & $\mathrm{F}$ & $\mathrm{F}$ & $\mathrm{F}$ & $\mathrm{F}$ \\
\hline & $x_{0}^{2}$ & 133 & 213 & 5.2076 & $9.94 \mathrm{E}-07$ & F & $\mathrm{F}$ & $\mathrm{F}$ & F & $\mathrm{F}$ & $\mathrm{F}$ & $\mathrm{F}$ & $\mathrm{F}$ \\
\hline & $x_{0}^{3}$ & 101 & 168 & 3.8083 & $8.27 \mathrm{E}-07$ & F & $\mathrm{F}$ & $\mathrm{F}$ & F & $\mathrm{F}$ & $\mathrm{F}$ & $\mathrm{F}$ & $\mathrm{F}$ \\
\hline & $x_{0}^{4}$ & 112 & 185 & 8.3720 & $8.91 \mathrm{E}-07$ & F & $\mathrm{F}$ & $\mathrm{F}$ & F & $\mathrm{F}$ & $\mathrm{F}$ & $\mathrm{F}$ & $\mathrm{F}$ \\
\hline & $x_{0}^{5}$ & 123 & 179 & 7.3988 & $9.91 \mathrm{E}-07$ & $\mathrm{~F}$ & $\mathrm{~F}$ & $\mathrm{~F}$ & F & $\mathrm{F}$ & $\mathrm{F}$ & $\mathrm{F}$ & $\mathrm{F}$ \\
\hline & $x_{0}^{6}$ & 132 & 220 & 8.7011 & $7.23 \mathrm{E}-07$ & F & $\mathrm{F}$ & $\mathrm{F}$ & $\mathrm{F}$ & $\mathrm{F}$ & $\mathrm{F}$ & $\mathrm{F}$ & $\mathrm{F}$ \\
\hline \multirow[t]{4}{*}{100000} & $x_{0}^{7}$ & 131 & 212 & 8.6776 & $7.57 \mathrm{E}-07$ & F & $\mathrm{F}$ & $\mathrm{F}$ & $\mathrm{F}$ & $\mathrm{F}$ & $\mathrm{F}$ & $\mathrm{F}$ & $\mathrm{F}$ \\
\hline & $x_{0}^{8}$ & 151 & 234 & 9.5741 & $8.54 \mathrm{E}-07$ & F & $\mathrm{F}$ & $\mathrm{F}$ & F & $\mathrm{F}$ & $\mathrm{F}$ & $\mathrm{F}$ & $\mathrm{F}$ \\
\hline & $x_{0}^{9}$ & 392 & 2982 & 68.1927 & $9.25 \mathrm{E}-07$ & $\mathrm{~F}$ & $\mathrm{~F}$ & $\mathrm{~F}$ & $\mathrm{~F}$ & $\mathrm{~F}$ & $\mathrm{~F}$ & $\mathrm{~F}$ & $\mathrm{~F}$ \\
\hline & $x_{0}^{10}$ & $\mathrm{~F}$ & $\mathrm{~F}$ & $\mathrm{~F}$ & $\mathrm{~F}$ & $\mathrm{~F}$ & $\mathrm{~F}$ & $\mathrm{~F}$ & $\mathrm{~F}$ & $\mathrm{~F}$ & $\mathrm{~F}$ & $\mathrm{~F}$ & $\mathrm{~F}$ \\
\hline
\end{tabular}

Acknowledgements. We would like to thank Professor Marcos Raydan for providing us with the MATLAB version of the dfsane code for numerical comparison. We gratefully acknowledge the educative suggestions and useful comments of the reviewers. The third author acknowledge with thanks, the Department of Mathematics and Applied Mathematics at the Sefako Makgatho Health Sciences University, Pretoria, South Africa. 


\section{REFERENCES}

[1] Y. Bing and G. Lin, An Efficient Implementation of Merrill's Method for Sparse or Partially Separable Systems of Nonlinear Equations. SIAM J. Optim. 1 (1991) 206-221.

[2] S. Deng and Z. Wan, A diagonal quasi-newton spectral conjugate gradient algorithm for nonconvex unconstrained optimization problems, In: Proceedings of the 5th International Conference on Optimization and Control with Applications. Curtin University (2012) 305-310.

[3] J.E. Dennis and J.J. Moré, A characterization of superlinear convergence and its application to quasi-Newton methods. Math. Comput. 28 (1974) 549-560.

[4] E.D. Dolan and J.J. Moré, Benchmarking optimization software with performance profiles. Math. Program. 91 (2002) 201-213.

[5] M.A. Gomes-Ruggiero, J.M. Martínez and A.C. Moretti, Comparing algorithms for solving sparse nonlinear systems of equations. SIAM J. Sci. Statist. Comput. 13 (1992) 459-483.

[6] A. Griewank and Ph.L. Toint, Local convergence analysis for partitioned quasi-newton updates. Numer. Math. 39 (1982) 429-448.

[7] A. Griewank and Ph.L. Toint, On the unconstrained optimization of partially separable functions, In: Nonlinear Optimization 1981. Academic press (1982) 301-312.

[8] A. Griewank and Ph.L. Toint, Partitioned variable metric updates for large structured optimization problems. Numer. Math. 39 (1982) 119-137.

[9] C.T. Kelly, A comparison of iteration schemes for chandrasekhar h-equations in multigroup neutron transport. J. Math. Phys. 21 (1980) 408-409

[10] N. Krejić, Z. Lužanin and I. Radeka, Newton-like method for nonlinear banded block diagonal system. Appl. Math. Comput. 189 (2007) 1705-1711.

[11] W. La Cruz and M. Raydan, Nonmonotone spectral methods for large-scale nonlinear systems. Optim. Methods Softw. 18 (2003) 583-599.

[12] W. La Cruz, J.M. Martínez and M. Raydan, Spectral residual method without gradient information for solving large-scale nonlinear systems: theory and experiments. Citeseer, Technical Report RT-04-08(https://www.ime.unicamp.br/ martinez/ lmrreport.pdf) (2004).

[13] W. La Cruz, J. Martínez and M. Raydan, Spectral residual method without gradient information for solving large-scale nonlinear systems of equations. Math. Comput. 75 (2006) 1429-1448.

[14] W.J. Leong, M.A. Hassan and M.W. Yusuf, A matrix-free quasi-Newton method for solving large-scale nonlinear systems. Comput. Math. with Appl. 62 (2011) 2354-2363.

[15] D. Li and M. Fukushima, A globally and superlinearly convergent Gauss-Newton-based BFGS method for symmetric nonlinear equations. SIAM J. Numer. Anal. 37 (1999) 152-172.

[16] L. Lukšan, C. Matonoha and J. Vlcek, Problems for nonlinear least squares and nonlinear equations. Technical report (2018).

[17] J.M. Martınez, Practical quasi-Newton methods for solving nonlinear systems. J. Comput. Appl. Math. 124 (2000) $97-121$.

[18] H. Mohammad, Barzilai-Borwein-like method for solving large-scale nonlinear systems of equations. J. Nigerian Math. Soc. 36 (2017) 71-83.

[19] H. Mohammad and M.Y. Waziri, On Broyden-like update via some quadratures for solving nonlinear systems of equations. Turk. J. Math. 39 (2015) 335-345.

[20] H. Mohammad and S.A. Santos, A structured diagonal Hessian approximation method with evaluation complexity analysis for nonlinear least squares. Comput. Appl. Math. (2018).

[21] J. Nocedal and S.J. Wright, Numerical Optimization. Springer Science (2006).

[22] Z.J. Shi and G. Sun, A diagonal-sparse quasi-Newton method for unconstrained optimization problem. J. Syst. Sci. Math. Sci. 26 (2006) 101-112.

[23] Z. Wan, Y. Chen, S. Huang and D. Feng, A modified nonmonotone BFGS algorithm for solving smooth nonlinear equations. Optim. Lett. 8 (2014) 1845-1860.

[24] M.Y. Waziri and Z. Abdul Majid, An improved diagonal Jacobian approximation via a new quasi-cauchy condition for solving large-scale systems of nonlinear equations. J. Appl. Math. 2013 (2013).

[25] M.Y. Waziri, W.J. Leong, M.A. Hassan and M. Monsi, Jacobian computation-free Newton's method for systems of non-linear equations. J. Numer. Math. Stoch. 2 (2010) 54-63.

[26] M.Y. Waziri, W.J. Leong, M. Mamat and A.U. Moyi, Two-step derivative-free diagonally Newton's method for large-scale nonlinear equations. World Appl. Sci. J. 21 (2013) 86-94.

[27] S. Wu and H. Wang, A modified Newton-like method for nonlinear equations. Comput. Appl. Math. 39 (2020) 1-18.

[28] G. Yu, S. Niu and J. Ma, Multivariate spectral gradient projection method for nonlinear monotone equations with convex constraints. J. Ind. Manag. Optim. 9 (2013) 117-129. 
[29] G. Yuan and X. Lu, A new backtracking inexact BFGS method for symmetric nonlinear equations. Comput. Math. Appl. 55 (2008) 116-129.

[30] L. Zhang, A derivative-free conjugate residual method using secant condition for general large-scale nonlinear equations. Numer. Algorithms 83 (2020) 1277-1293.

\section{Subscribe to Open (S20) A fair and sustainable open access model}

This journal is currently published in open access under a Subscribe-to-Open model (S2O). S2O is a transformative model that aims to move subscription journals to open access. Open access is the free, immediate, online availability of research articles combined with the rights to use these articles fully in the digital environment. We are thankful to our subscribers and sponsors for making it possible to publish this journal in open access, free of charge for authors.

\section{Please help to maintain this journal in open access!}

Check that your library subscribes to the journal, or make a personal donation to the S2O programme, by contacting subscribers@edpsciences.org

More information, including a list of sponsors and a financial transparency report, available at: https://www. edpsciences.org/en/maths-s2o-programme 